\title{
A chemical mechanism for low to high temperature oxidation of methylcyclohexane as a component of transportation fuel surrogates
}

\author{
Krithika Narayanaswamya,*, Heinz Pitsch $^{\mathrm{b}}$, Perrine Pepiot ${ }^{\mathrm{a}}$ \\ ${ }^{a}$ Sibley School of Mechanical and Aerospace Engineering, Cornell University, NY 14853 \\ ${ }^{b}$ Department of Mechanical Engineering, RWTH, Aachen, Germany
}

\begin{abstract}
Surrogate fuels consisting of a mixture of well-studied hydrocarbons are often used to model real fuels in typical combustion studies. A major challenge, however, is the capability to design compact and reliable kinetic models that capture all the specificities of the simpler, but still multi-component surrogates. This task is further complicated by the diverse nature of the hydrocarbons commonly considered as potential surrogate components, since they typically result in large detailed reaction schemes. Towards addressing this challenge, the present work proposes a single, compact, and reliable chemical mechanism, that can accurately describe the oxidation of a wide range of fuels, which are important components of surrogate fuels. A well-characterized mechanism appropriate for the oxidation of smaller hydrocarbon species [Blanquart et al., Combust. Flame (2009)], as well as several substituted aromatic species and $n$-dodecane [Narayanaswamy et al., Combust. Flame (2010, 2014)], well suited as a base to model surrogates, has now been extended to describe the oxidation of methylcyclohexane, a representative of the cyclic alkane class, which is often used in jet fuel surrogates. To ensure compactness of the kinetic scheme, a short mechanism for the low to high temperature oxidation of methylcyclohexane is extracted from the detailed scheme of Pitz et al. [Proc. Combust. Inst. (2007)] and integrated in a systematic way into the previous model. Rate coefficient changes based on recent recommendations from literature, and an additional concerted elimination pathway important at moderate to low temperatures are introduced to the resulting chemical mechanism, which improve the model predictions. Extensive validation of the revised kinetic model is performed using a wide range of experimental conditions and data sets.
\end{abstract}

Keywords: Chemical mechanism, kinetics, cyclic alkanes, fuel surrogates, methylcyclohexane

\section{Introduction}

Computational combustion studies in engines typically use surrogates to model real fuels. However, it is challenging to develop kinetic models that describe the oxidation of all individual components in multi-component surrogates accurately. Further, the nature of the hydrocarbons commonly considered as surrogate components often leads to extremely large reaction schemes for surrogate mixtures, owing to the large detailed reaction schemes for the individual component description. As a result, designing compact kinetic models is yet another formidable task. Our objective is to meet these challenges, by developing a single, consistent, reliable, and compact chemical mechanism that can describe the oxidation of essential components of transportation fuel surrogates. The present work expands on our previous efforts providing a good foundation for the development of fuel surrogates.

Previously, a single chemical mechanism describing the oxidation of a wide range of hydrocarbon species, from $\mathrm{C}_{1}$

\footnotetext{
* Corresponding Author
}

Email: kn295@cornell.edu to $\mathrm{C}_{8}$ species (called the "base" mechanism in the following) was developed and validated extensively against experimental data for the oxidation of several compounds, including $n$-heptane and iso-octane [1, with emphasis on detailed soot modeling and surrogate fuel formulations. In addition to smaller hydrocarbons, which are well described in that model, jet fuels consist of up to $16-18 \%$ of aromatic compounds 2, 3, and these play a crucial role in soot formation. Accordingly, the mechanism was extended in a consistent manner to describe the moderate to high temperature oxidation of several aromatics, viz. toluene, ethylbenzene, styrene, $m$-xylene, and $\alpha$-methylnaphthalene [4. The resulting scheme was validated thoroughly against available experimental data for the substituted aromatics under consideration, including (i) ignition delay data [5-12, (ii) species profiles in shock tubes [12 14, (iii) species profiles in flow reactors 15 18, and (iv) laminar burning speed data $19 \sqrt{22}$.

Very recently, this reaction mechanism was further extended to include the low to high temperature oxidation pathways of $n$-dodecane [23]. The prime objective of this work is to extend this mechanism, hereafter referred to as the base+aromatics+dodecane model, well suited as a starting point to model surrogate blends, to include the 
low to high temperature oxidation pathways of a representative of the cyclic alkane class. Cyclic alkanes, or naphthenes, are important components of practical transportation fuels, and account for up to $40 \%$ in conventional diesel fuels and up to $20 \%$ in conventional jet fuels [2426. Naphthenes are also found to play a key role in the formation of soot precursors [27]. The ring structure of these cyclic molecules allows certain pathways (for instance, opening of the cyclic ring) that are not possible in linear/branched alkanes/alkenes and therefore, potentially influence the reactivity of the real fuel. This article focuses on the development of a compact multi-component kinetic model that includes one such cyclic alkane, leaving the formulation and validation of surrogates for future work.

Substituted cyclic alkanes, such as methyl, ethyl, $n$ propyl cyclohexane, and bicyclic alkanes, such as tetralin, are potential candidates to represent this class of compounds in transportation fuel surrogates. Out of these, methylcyclohexane is chosen as the naphthene representative for this work, because it is the simplest substituted cyclic alkane that can be modeled reliably: the global ignition and flame propagation characteristics of methylcyclohexane have been examined in several experimental studies, and some of the key chemical reaction pathways encountered during its oxidation have also been the object of theoretical and experimental kinetic rate constant determinations.

There have been several kinetic modeling efforts directed towards methylcyclohexane chemistry, which are discussed here in chronological order. Granata et al. 28] proposed a semi-lumped reaction mechanism including low temperature chemistry to describe the pyrolysis and oxidation of cyclohexane and extended this model to describe methylcyclohexane kinetics as well. They validated the methylcyclohexane chemistry against pyrolysis and oxidation data from the Princeton turbulent flow reactor experiments [29]. Later, Orme et al. [30] proposed a detailed high temperature mechanism for the oxidation of methylcyclohexane, and validated the kinetic scheme against ignition delays obtained in their shock tube experiments, as well as flow reactor experiments 29].

Following this, Pitz et al. 31] proposed a reaction mechanism for methylcyclohexane oxidation valid for low through high temperatures by adding the low temperature reaction pathways for methylcyclohexane oxidation to the high temperature reaction mechanism developed by Orme et al. 30. The resulting chemical scheme was validated against ignition delay time data from their rapid compression machine studies at temperatures $T<1000 \mathrm{~K}$. However, the test cases considered in the parent Orme et al. model were not reconsidered using the Pitz et al. model. In an ongoing effort towards a jet fuel surrogate mechanism, the JetSurF 32 model has the capability to describe the high temperature chemistry of methylcyclohexane, and has been tested widely against experimental data at high temperatures. Recently, two more studies provided experimental data and kinetic modeling for methylcyclohexane. Wang et al. 33. proposed a kinetic model applicable at high temperatures and validated this model against species profiles in premixed flames, ignition delays, and laminar flame speeds. Weber et al. 34 updated the Pitz et al. model 31. with changes to the low temperature chemistry, resulting in improved ignition delay predictions.

Considering the experimental investigations on methylcyclohexane oxidation, in addition to the data sets referred above 29 31], the relevance of methylcyclohexane as a component of jet fuel surrogates has recently attracted a number of experimental studies, thus widening the experimental database on methylcyclohexane oxidation [33, 3542. A majority of these experimental data were obtained after the development of the above mentioned models, and those models were not validated against all available data, for example, species profile measurements and ignition delays in the Negative Temperature Coefficient (NTC) region. There is therefore a rich experimental database that has yet to be fully utilized for model evaluation and improvement.

Our objective is to (i) leverage this recent experimental knowledge to develop and extensively validate a model for low through high temperature oxidation of methylcyclohexane, (ii) ensure that the proposed reaction scheme retains a compact size, as a kinetic scheme with a reasonably small number of species (say $<500$ ) permits certain calculations, such as calculation of laminar flame speeds, detailed species profiles in flames, sensitivity analysis, and integration in CFD simulations (for example, using tabulation methods), which become very tedious with larger reaction mechanisms, and (iii) arrive at a single chemical mechanism that can accurately describe the oxidation of a wide range of fuels, which are important surrogate components. The present model is built as an additional module on a consistent well-validated model developed in stages [1, 4, 23, and thereby ensures kinetic compatibility between the various individual components included in the multi-component scheme by construction.

To ensure the compactness of the present reaction scheme, only the kinetics essential to describe the low through high temperature oxidation pathways of methylcyclohexane are introduced into the base+aromatics+dodecane model [23]. Mechanism reduction techniques developed previously by Pepiot and Pitsch [43, 44] are employed to first obtain a reduced reaction scheme applicable to low through high temperature oxidation of methylcyclohexane, which is then combined with the base+aromatics +dodecane model. Since the chemical mechanisms being combined are small in size, the risk of introducing truncated paths or involuntarily duplicating reaction pathways in the combined mechanism is best circumvented by this approach. The reader is referred to Ref. 23. for a detailed discussion on the pros and cons of the procedure adopted here to integrate the reaction pathways of a new fuel into an existing mechanism.

In the present work, the detailed reaction scheme proposed by Pitz et al. 31] is chosen as the reference mechanism to obtain a short mechanism for methylcyclohex- 
ane. This kinetic scheme describes the entire low through high temperature chemistry of methylcyclohexane as described above. While significant effort has gone into developing the Wang et al. 33 model and the JetSurF 32 model that describe the oxidation of methylcyclohexane, since low temperature chemistry is also of interest here, for consistency, it is found best to start with a reaction mechanism that already includes these pathways. Also, the detailed mechanism of Pitz et al. is constructed from elementary reactions, which makes it preferable for the aforementioned mechanism reduction approach, over the Granata et al. 28, model, which is semi-lumped in nature. Since the present work was completed before the very recent Weber et al. 34 model (with updates to the Pitz et al. 31 model) was proposed, this mechanism could not be considered as a starting point for the present mechanism development.

The paper is organized as follows. Section 2.1 describes the short skeletal level reaction mechanism for methylcyclohexane obtained using the reduction procedure. Thereafter, section 2.2 describes the combined model obtained upon merging this short mechanism with the existing base+ aromatics +dodecane model. In section 2.3. the methylcyclohexane kinetics in the resulting model are updated based on recent theoretical and experimental studies, and an additional pathway important at moderate to low temperatures is introduced. A comprehensive assessment of the performance of the revised reaction model for different targets is then discussed in section 3. Note that the phrase "model predictions" used in the manuscript refers to the results obtained using the corresponding kinetic model.

\section{Mechanism development}

\subsection{Skeletal model}

The reference mechanism for methylcyclohexane oxidation from Pitz et al. 31] has 8807 forward and reverse reactions among 999 species. First, this detailed mechanism is reduced to a skeletal level using a multi-stage reduction strategy, involving species and reaction elimination using the DRGEP approach 43 and chemical isomer lumping 44]. In this reduction technique, each reduction step, i.e. elimination of species, additional elimination of reactions, and lumping (mostly of chemical isomers), is performed in one sweep with a single evaluation of source terms at the considered conditions. This technique therefore avoids reduction by cancellation of errors, and instead only neglects species and reactions that have truly a small influence on the reaction fluxes.

The database used to carry out the reduction includes homogeneous, adiabatic, isobaric, and isochoric reactor configurations at low to high temperatures $(T=600-1500$ $\mathrm{K})$, pressures ranging from $P=1-40 \mathrm{~atm}$, and equivalence ratios spanning lean to rich conditions $(\phi=0.5-1.5)$. The species profiles of fuel, oxidizer, and major combustion products, as well as ignition delays (defined using the extrapolation of the maximum gradient in computed temperature to the baseline) are used as targets in the reduction process.

In the DRGEP method 43] for species and reaction elimination, production rates obtained from the reference chemical mechanism are analyzed in order to quantify the coupling between the various species and reactions involved. These interactions are represented by a directed relation graph, and used to identify the important species and pathways for a given set of targets, using an error propagation strategy. All chemical pathways are checked during the reduction process to avoid truncated chemical paths and mass accumulation in intermediate species. Using DRGEP, a reduced mechanism, consisting of 300 species and 1272 reactions is thereby extracted from the detailed Pitz et al. 31] model.

Lumping the numerous isomer species into a smaller number of representative species is essential to the development of compact schemes for methylcyclohexane oxidation. In the chemical lumping method from Pepiot and Pitsch 44] adopted here, simulations using the above reduced reaction scheme are used to gather statistical information on the distribution of the isomers within each lump group over the range of conditions considered in the reduction. The dependence of the isomer distributions on the temperature is considered, and optimal correcting factors are incorporated into the Arrhenius form of the rate coefficients of lumped reactions. Note that the values of A-factor, temperature coefficient, and $\mathrm{E}_{\mathrm{act}}$ are fitted to best account for the correcting factor, and may differ significantly from the original elementary rate coefficients.

The choice of isomers to be lumped together was found to be crucial to correctly reproduce the ignition delay times at $T<1000 \mathrm{~K}$. As proposed by Ahmed et al. [45], and successfully used in Pepiot and Pitsch 44 and Narayanaswamy et al. 23, the isomers of species important at these lower temperatures have been grouped here according to the size of the ring involved in the transition state of the corresponding isomerization reactions. Thus, by choosing isomers that react through similar pathways to be grouped together, the lumped rate constants accurately represent the actual total rate constant for the lumped species, resulting in little errors due to lumping. The radicals of methylcyclohexane, and the corresponding peroxy radicals formed from the addition of $\mathrm{O}_{2}$ molecule to these radicals are retained as individual species to facilitate the model improvements discussed in section 2.3 .

Also, isomers of smaller species $\left(<\mathrm{C}_{4}\right)$ have been exempted from lumping. While large isomers usually have similar production and consumption routes (thus justifying lumping these isomers together), this is not the case for smaller molecules, and lumping these is not justified chemically. Also, those isomers in the detailed model that exist as individual species in the base model are not lumped to ensure kinetic compatibility between the two models. Upon lumping, a reduced reaction mechanism consisting of 268 species and 1202 reactions is obtained. 
An additional step of species and reaction elimination is then performed on the lumped reaction mechanism as recommended in Refs. 44, 46. The final skeletal level mechanism consists of 1000 reactions among 253 species.

The significant size reduction for the kinetic scheme introduces only limited errors in the model predictions, the maximum error in ignition delays being $\sim 14 \%$ at the lowest temperature point considered, with an average error of $\sim 4 \%$, and the time integrated error in species concentrations being $\sim 6 \%$ compared to the reference detailed mechanism. The good agreement between the detailed and skeletal model prediction is illustrated in Fig. 1(a), with a comparison of ignition delays over a wide range of temperatures and pressures, and in Fig. 1(b), with a comparison of fuel and $\mathrm{CO}_{2}$ time histories obtained in a flow reactor. This skeletal scheme is used in the subsequent mechanism development steps.

\subsection{Combined model}

The next step is to combine the skeletal mechanism for methylcyclohexane with the base+aromatics+dodecane mechanism [23, which already incorporates the most recent $\mathrm{H}_{2} / \mathrm{O}_{2}$ chemistry of Burke et al. [47]. As described earlier, this kinetic scheme has the capability to describe the oxidation of a few substituted aromatics as well as $n$-heptane, iso-octane, and $n$-dodecane, which are all key components of transportation fuel surrogates. Once the pathways of methylcyclohexane, which is typically chosen as a cyclic alkane representative in fuel surrogates, are incorporated in this reaction mechanism and validated extensively, the resulting kinetic scheme should be well suited as a basis to describe surrogates for real fuels.

The merging of the skeletal methylcyclohexane model with the base+aromatics +dodecane mechanism [23] is accomplished using an interactive tool 46 that automatically identifies common species and reactions from the different mechanisms, and incompatibilities between the kinetic data sets. The same reactions are often times assigned different rate parameters by kinetic modelers due to (i) underlying assumptions, for instance, about bond strengths, (ii) differences from fitting reverse rate constants from thermo data, (iii) uncertainty in measured or calculated rate coefficients, etc. In order to ensure a smooth and consistent merging, rate constant conflicts detected during the merging were always resolved in favor of the thoroughly validated base model [4, therefore leaving this mechanism virtually unchanged. For instance, the $\mathrm{H}_{2} / \mathrm{O}_{2}$ chemistry in the skeletal methylcyclohexane mechanism is different from that in our base model, and the combined model uses the $\mathrm{H}_{2} / \mathrm{O}_{2}$ chemistry from the recent Burke et al. 47 incorporated in our base model. Further, duplicate reaction pathways in the combined model coming from the incremental methylcyclohexane reaction scheme were identified and removed appropriately. Finally, the validation tests for the substituted aromatics and $n$ dodecane presented in our previous works 4, 23 were repeated using the combined mechanism, and only minor changes were observed in the model predictions. In the combined mechanism, excluding those reactions comprising the base+aromatics +dodecane model, the incremental methylcyclohexane sub-mechanism consists of 397 reactions (counted forward and backward separately) among 116 species.

A sketch of the main oxidation pathways of the fuel (methylcyclohexane) and the ring opening of methylcyclohexyl radicals in the combined mechanism is shown in Fig. 2(a), The low temperature reaction pathways for one of the methylcyclohexyl radicals retained in the methylcyclohexane sub-mechanism are provided in Fig. 2(b), and additional diagrams are shown in the Supplementary materials (Figs. S1 and S2). A more detailed and quantitative reaction path analysis for a representative condition will be discussed in section 3.3 .

\section{Need for an improved model}

Ignition delays at low through high temperatures and species profiles measured in shock tube experiments are two of the targets that the model should be able to predict. The ignition delays computed using the combined mechanism are compared against data from the shock tube experiments of Vasu et al. [48] at $\phi=1.0$ and $P=20 \mathrm{~atm}$ in Fig. 3(a). The ignition delays at low temperatures measured in Rapid Compression Machines (RCM) by Pitz et al. 31 are also plotted in this figure. The ignition delay predictions of the combined model are closer to the experimental ignition delay data at low through high temperatures compared to the skeletal model, due to the differences in the $\mathrm{C}_{0}-\mathrm{C}_{4}$ base chemistry. From Fig. 3(a) it can be noted that both these models predict ignition delays which are longer compared to the experimental data at all temperatures, except at the low temperatures $T<700 \mathrm{~K}$, where the agreement with the experimental data is satisfactory.

In Fig. 3(b), $\mathrm{OH}$ time histories computed using the combined model and the skeletal model are shown in comparison to the shock tube measurements from Vasu et al. 49. Although the pathways producing and consuming $\mathrm{OH}$ are similar in the skeletal as well as the combined models, the higher $\mathrm{OH}$ yield predicted by the combined model comes from the differences in rate constants for the $\mathrm{C}_{0}-\mathrm{C}_{2}$ chemistry. Furthermore, Fig. 3(b) shows that the rise of $\mathrm{OH}$ profiles computed using the combined model occurs later and without any noticeable peak, in contrast to the experimental data. These observations certainly highlight the need for improvement to the combined model.

The kinetic mechanism at this stage of development is referred to as the $C P M$ model (for combined, prior to modifications) in the following. In order to improve the kinetic description of methylcyclohexane oxidation, and thereby the predictive capabilities of this model, a small number of corrections and rate constant updates are introduced. The updates are primarily based on recent rate recommendations from theoretical and experimental work 


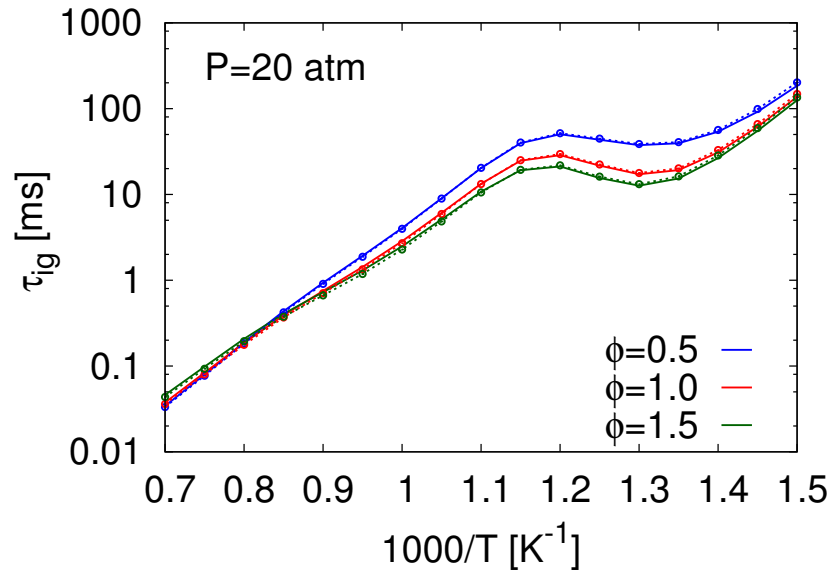

(a) Ignition delays

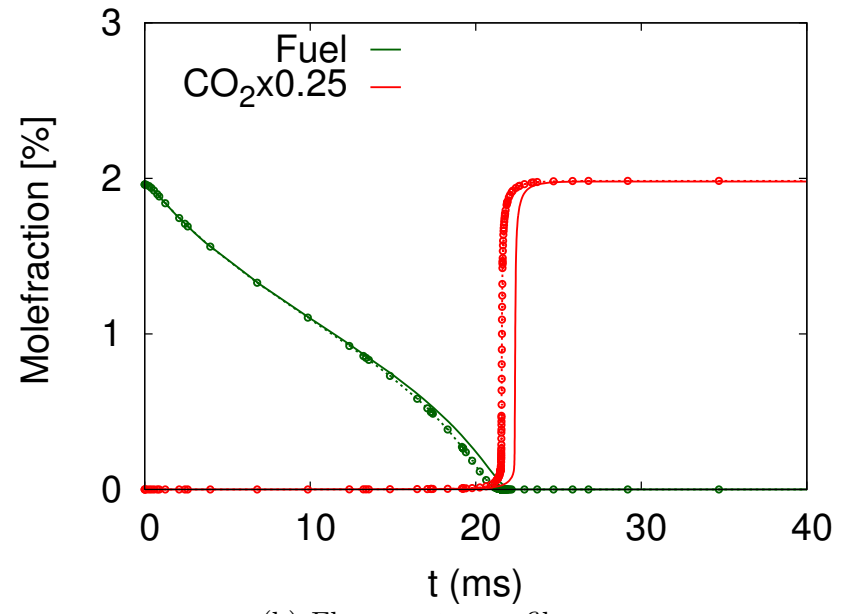

(b) Flow reactor profiles

Figure 1: Comparing (a) ignition delay times of methylcyclohexane/air mixtures and (b) species profiles during methylcyclohexane oxidation $(P=1 \mathrm{~atm}, T=1100 \mathrm{~K}, \phi=1.0)$ between the detailed model of Pitz et al. 31] (lines) and the corresponding 253 species skeletal model (o), prior to combining with the base + aromatics + dodecane model [23].

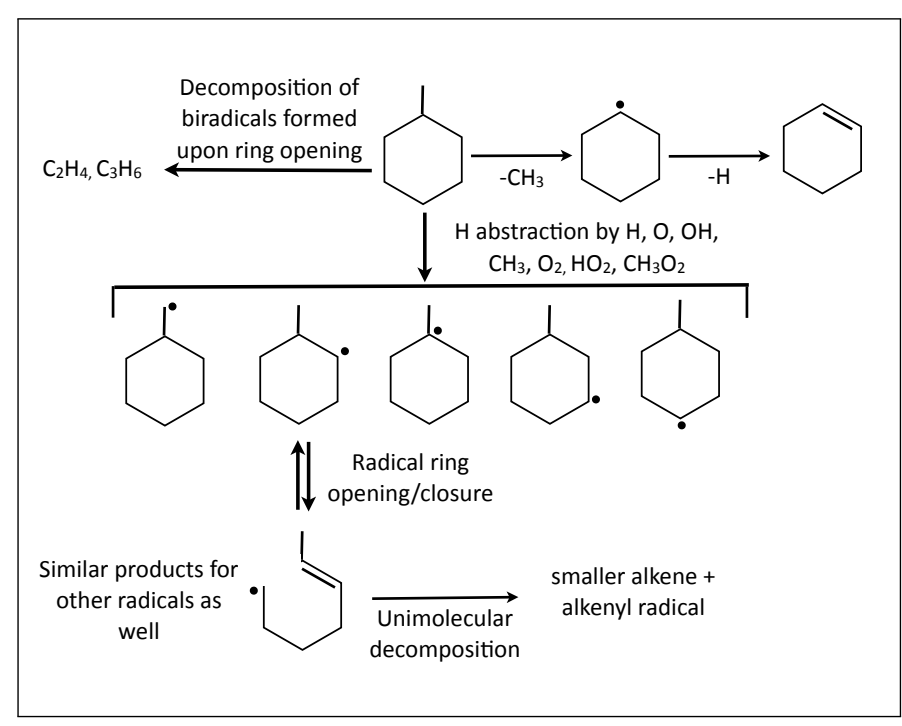

(a) Fuel and radical decomposition pathways

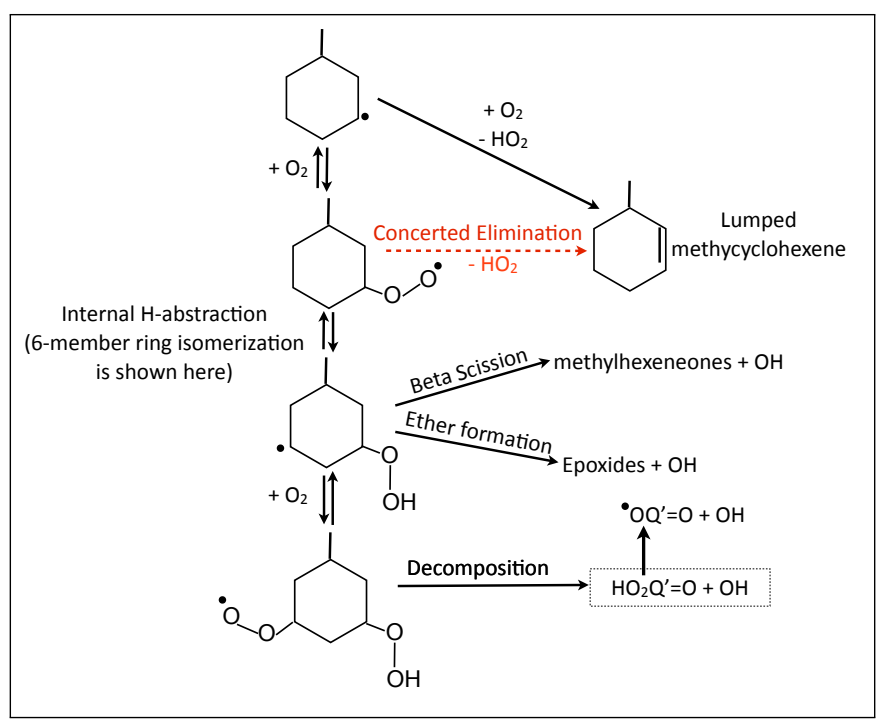

(b) Pathways for low temperature chemistry

Figure 2: (a) Main oxidation pathways of methylcyclohexane and the ring opening of methylcyclohexyl radicals (b) Low temperature reaction pathways for one of the methylcyclohexyl radicals retained in the combined model, which is the reaction mechanism obtained by merging the skeletal level methylcyclohexane mechanism with the base + aromatics + dodecane model 23] (see text for details). The concerted elimination pathways indicated using dashed lines in (b) are newly introduced in the proposed kinetic scheme, which will be discussed in section 2.3 


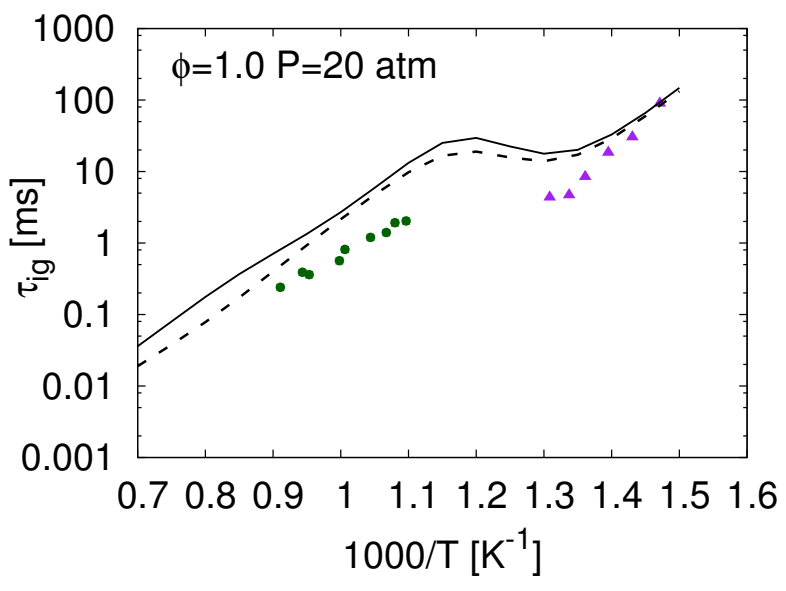

(a) Ignition delay times

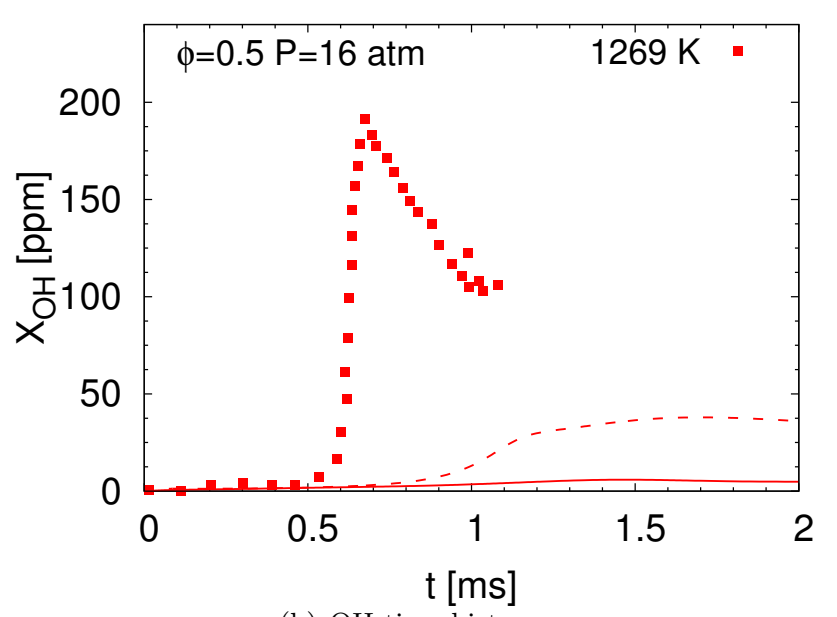

(b) $\mathrm{OH}$ time history

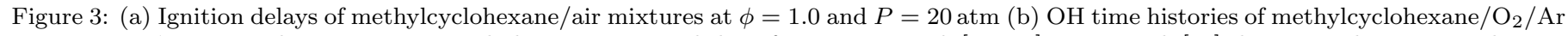
mixtures at $\phi=0.5$ and $P=15$ atm; symbols - experimental data from Vasu et al. 48 [49, Pitz et al. [31; lines: results computed using the (i) skeletal model (-), obtained by reducing the detailed Pitz et al. 31] model, and (ii) combined model (-- -), obtained by merging the skeletal model with the base + aromatics + dodecane model [23.

available in the literature. An additional pathway important at moderate to low temperatures is also introduced. The following sub-section discusses these updates in detail.

\subsection{Modifications to the reaction mechanism}

The revisions introduced to the reaction mechanism are primarily guided by sensitivity studies, which is facilitated by the relatively small size of the reaction scheme. A sensitivity study on the $C P M$ model is used to identify the reactions with a high sensitivity towards ignition delays at low to high temperatures. The rate constants of these sensitive reactions have been checked and updated wherever possible, irrespective of whether the update leads to an improvement of the ignition delay and the species profiles predictions or a deterioration. The rate constant changes are also guided by reaction flux analysis performed using the CPM model. These revisions are described in detail here.

The results of the sensitivity analysis on the CPM model for a stoichiometric methylcyclohexane/air mixture at $P=20 \mathrm{~atm}$ and $T=1250 \mathrm{~K}, 800 \mathrm{~K}$ are shown in Fig. 4. The molecular structures of the species referred to in the following discussion are shown in Fig. 5 .

A. Biradical pathways First, the ring-opening pathways of methylcyclohexane to form biradicals are considered. The detailed mechanism of Pitz et al. [31, and therefore the CPM model, includes pathways, by which the different $\mathrm{C}_{7} \mathrm{H}_{14}$ biradicals formed from the ring-opening of methylcyclohexane, decompose into butyl and pentyl biradicals, with the formation of propene and ethylene, as

$$
\begin{aligned}
\mathrm{C}_{7} \mathrm{H}_{14} 16 & \rightleftharpoons \mathrm{C}_{4} \mathrm{H}_{8} 14+\mathrm{C}_{3} \mathrm{H}_{6}, \\
\mathrm{C}_{7} \mathrm{H}_{14} \mathrm{AF} & \rightleftharpoons \mathrm{C}_{4} \mathrm{H}_{8} 14+\mathrm{C}_{3} \mathrm{H}_{6}, \\
\mathrm{C}_{7} \mathrm{H}_{14} 16 & \rightleftharpoons \mathrm{C}_{5} \mathrm{H}_{10} 14+\mathrm{C}_{2} \mathrm{H}_{4}, \text { and } \\
\mathrm{C}_{7} \mathrm{H}_{14} \mathrm{GL} & \rightleftharpoons \mathrm{C}_{5} \mathrm{H}_{10} 14+\mathrm{C}_{2} \mathrm{H}_{4} .
\end{aligned}
$$

The butyl biradical then decomposes to give two ethylene molecules, while the pentyl biradical gives an ethylene and a propene molecule, as

$$
\begin{aligned}
\mathrm{C}_{4} \mathrm{H}_{8} 14 & \rightleftharpoons \mathrm{C}_{2} \mathrm{H}_{4}+\mathrm{C}_{2} \mathrm{H}_{4}, \text { and } \\
\mathrm{C}_{5} \mathrm{H}_{10} 14 & \rightleftharpoons \mathrm{C}_{2} \mathrm{H}_{4}+\mathrm{C}_{3} \mathrm{H}_{6} .
\end{aligned}
$$

Recent studies on the isomerization of methylcyclohexane via ring-opening [33, 40, 50] have established that methylcyclohexane forms linear heptenes and methyl hexenes via biradical intermediates, as against ethylene and propene formed as products in reactions (1)-(4). Following this, in the present work, the biradical intermediates are bypassed, and the pathways for methylcyclohexane isomerization to give linear heptenes as products are included, with rate coefficients taken from the theoretical calculations of Zhang et al. 50. In the absence of methyl hexene chemistry in the present mechanism, the reactions leading to the formation of methyl hexenes from methylcyclohexane are ignored, which could be justified, since the rates for the formation of the linear heptenes dominate (about 10 times at $1400 \mathrm{~K}$ ) those for the branched alkenes, as inferred from the rate constant calculations of Zhang et al. [50.

As shown in Fig. 6(a), this change results in faster ignition delay predictions at temperatures $T>1000 \mathrm{~K}$. This revision, guided by reaction flux analysis (discussed in section 3.2 is also found to be important to predict $\mathrm{OH}$ profiles in shock tube experiments. 

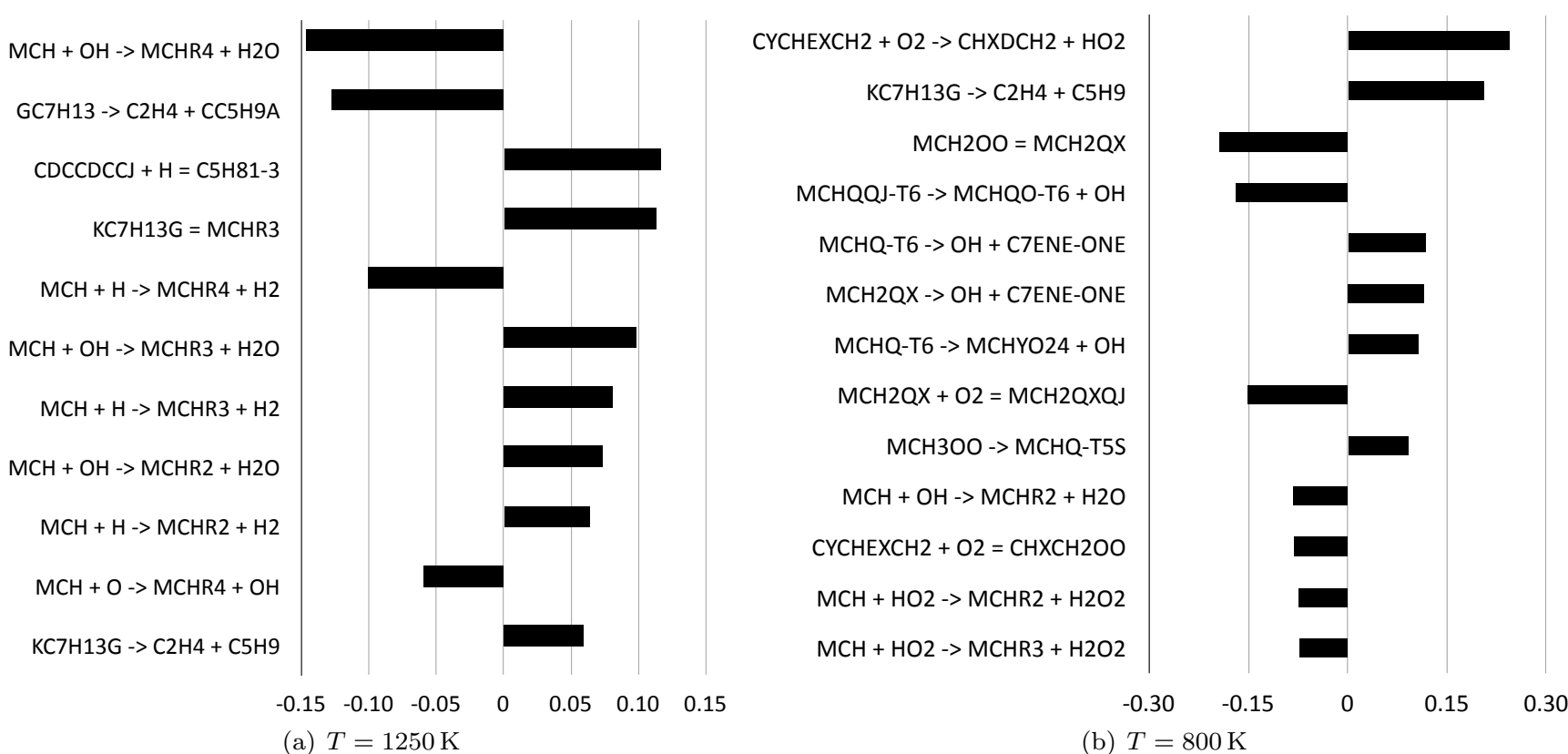

(b) $T=800 \mathrm{~K}$

Figure 4: Sensitivity analysis for ignition delays of methylcyclohexane/air mixtures at $\phi=1.0$ and $P=20$ atm using the $C P M$ model described in section 2.2 Sensitivities are determined by multiplying each rate constant by a factor of 2 , and finding the change in ignition delays due to the rate change. Only reactions in the incremental $\mathrm{MCH}$ mechanism with sensitivity factor $\gtrsim 7 \%$ at $1250 \mathrm{~K}$ and $800 \mathrm{~K}$ are reported here. The names of species that are not lumped are similar to those used in the original Pitz et al. 31] mechanism. Refer to Tables S1-S3 in the Supplementary materials for a description of the generic names used for the lumped species in this figure.

B. Addition of $\mathbf{C}_{2} \mathbf{H}_{3}$ to $\mathbf{C}_{3} \mathbf{H}_{6}$ A correction to the rate constant of $\mathrm{C}_{2} \mathrm{H}_{3}$ addition to the internal double bonded carbon in $\mathrm{C}_{3} \mathrm{H}_{6}$ to give the branched alkenyl $\mathrm{cC}_{5} \mathrm{H}_{9}$ a radical,

$$
\mathrm{C}_{2} \mathrm{H}_{3}+\mathrm{C}_{3} \mathrm{H}_{6} \rightleftharpoons \mathrm{cC}_{5} \mathrm{H}_{9} \mathrm{a} \text { (3-methyl-1-penten-4-yl), }
$$

is introduced in the model based on the rate rules from Orme et al. [30. As noted from Fig. 6(b), this change results in longer ignition delays at high temperatures, $T>$ $1000 \mathrm{~K}$ with little effect at lower temperatures.

C. Ring opening of radicals of methylcyclohexane We consider the ring opening of cyclohexylmethyl and methylcyclohexyl radicals (see Fig. 2(a) next. The original Orme et al. 30, and Pitz et al. 31. models obtained the rate constants for the ring closure of different $\mathrm{C}_{7} \mathrm{H}_{13}$ radicals to form methylcyclohexyl and cyclohexylmethyl radicals from Matheu et al. [51]. The reverse rate constant for methylcyclohexyl radical ring opening was calculated from the thermochemical properties. Recent theoretical calculations at the CBS-QB3 level of theory performed by Sirjean et al. [52 have focussed on similar reactions for cyclohexyl radicals. Those authors obtained lower rates (by a factor of 6 at $500 \mathrm{~K}$ ) for the ring closure reactions of cyclohexyl radicals compared to Matheu et al., and attributed the differences to the lower computational level of theory used in the Matheu et al. calculations for these reactions.
In the present chemical mechanism, the rate constants for the ring opening and closing reactions involving the radicals of methylcyclohexane are updated from the quantum chemical calculations of Sirjean et al. 52 for the corresponding cyclohexyl radical reactions, independent of the nature of the $\mathrm{C}-\mathrm{C}$ bond that breaks (for instance, $2^{\circ}-$ $2^{\circ} \mathrm{C}$ bond in MCHR2 $\rightarrow \mathrm{gC}_{7} \mathrm{H}_{13}$ l, whereas $3^{\circ}-2^{\circ} \mathrm{C}$ bond in MCHR2 $\left.\rightarrow \mathrm{C}_{7} \mathrm{H}_{13}\right)$. This modification results in shorter ignition delays in the NTC ignition regime, $780 \mathrm{~K}<T<$ $900 \mathrm{~K}$, as seen from Fig. 6(c). The rate coefficients for cyclohexyl radical ring opening and closure are also updated based on Sirjean et al. 52, although this change does not affect the ignition delay results significantly.

D. Decomposition of $\gamma$-QOOH radicals Figure 4(b) shows that the ignition delay predictions at moderate temperatures $(T \sim 800 \mathrm{~K})$ are highly sensitive to the $\beta$-scission of $\gamma$-QOOH radicals (see Fig. 5(d) for an example), where the radical site is at the $\gamma$-position to the $\mathrm{OOH}$ group in the hydroperoxy radical. The rate assigned to this decomposition reaction in the detailed mechanism of Pitz et al. 31 is that of the reverse rate calculated from the ring closing of the $\mathrm{C}=\mathrm{CCCC}(\mathrm{C}) \mathrm{C}^{\bullet} \mathrm{OOH}$ radical. In the present work, this rate constant is updated based on the rate of the cyclohexyl ring opening from Sirjean et al. [52], ignoring the $\mathrm{OOH}$ group present in $\gamma$-QOOH. This change results in shorter ignition delays in the NTC ignition regime, $780 \mathrm{~K}<T<1000 \mathrm{~K}$, as shown in Fig. 6(d) 


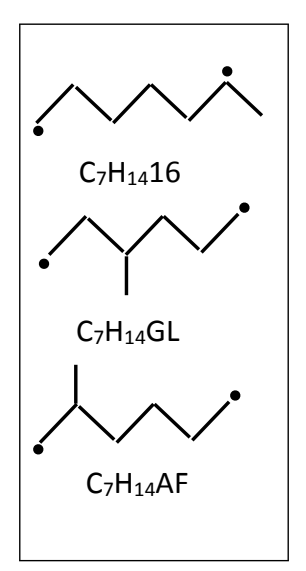

(a) Biradicals

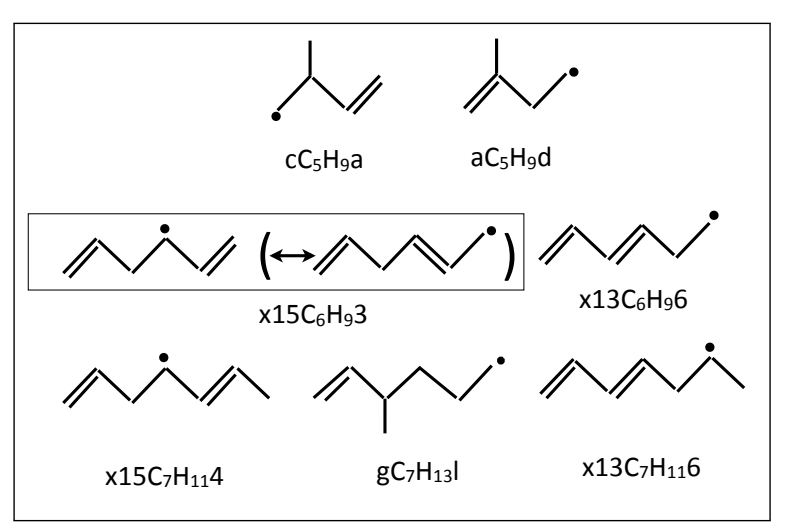

(b) Alkenyl radicals

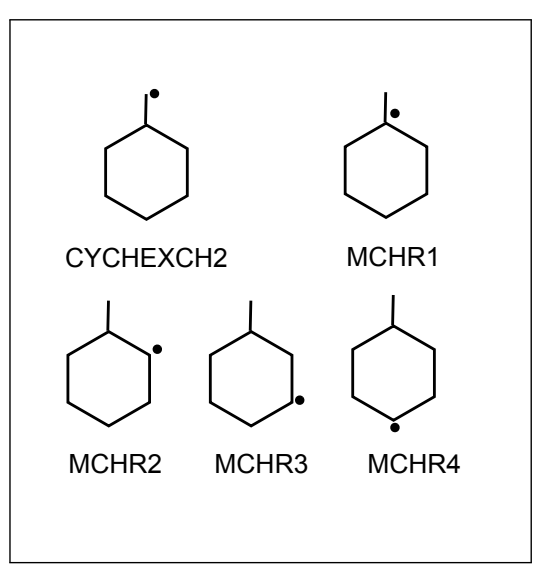

(c) Radicals of methylcyclohexane

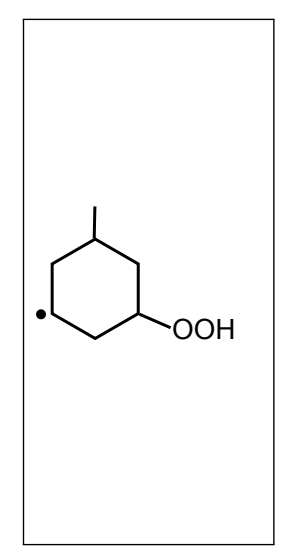

(d) Example of a $\gamma$-QOOH radical

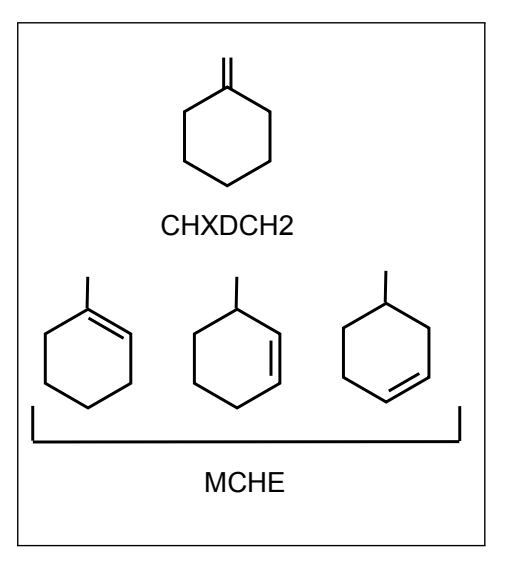

(e) Alkenes

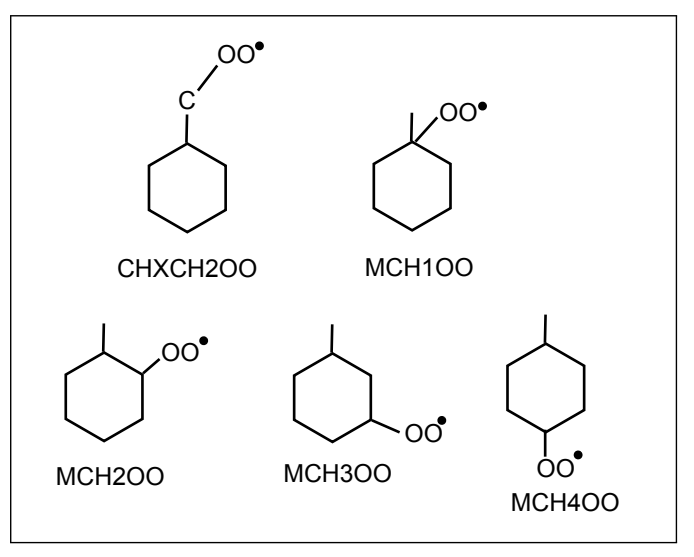

(f) Peroxy radicals

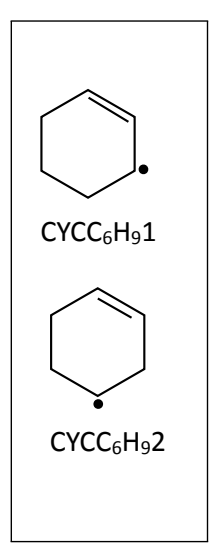

(g) Cyclohexenyl radicals

Figure 5: Chemical structure of the molecules referred in the discussion of section 2.3 The nomenclature follows that used by Pitz et al. 31 in their detailed mechanism. The structures are indicated here only for the sake of reference, and the bond lengths and angles are not drawn to scale. 


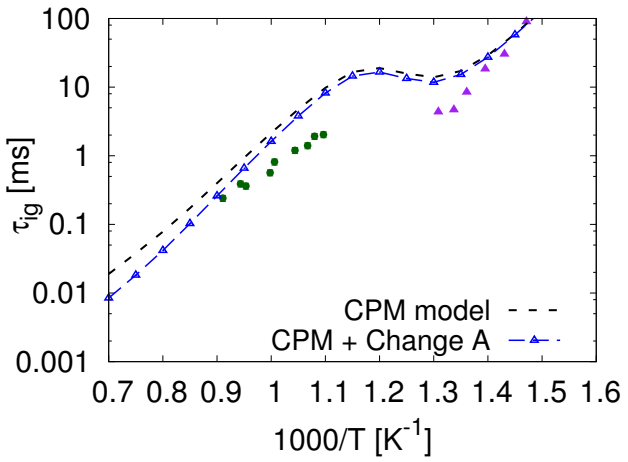

(a) Effect of Change A

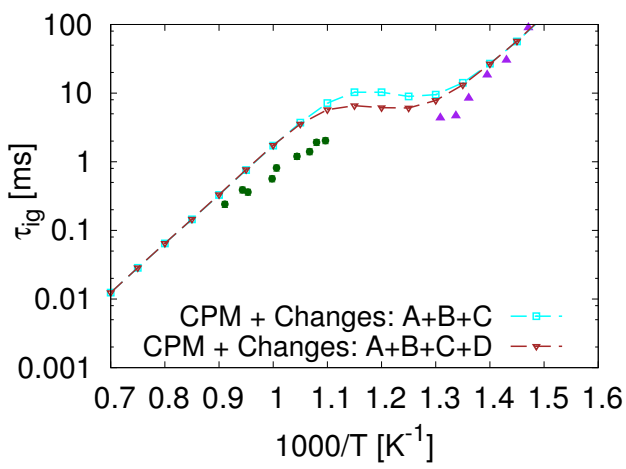

(d) Effect of Change D

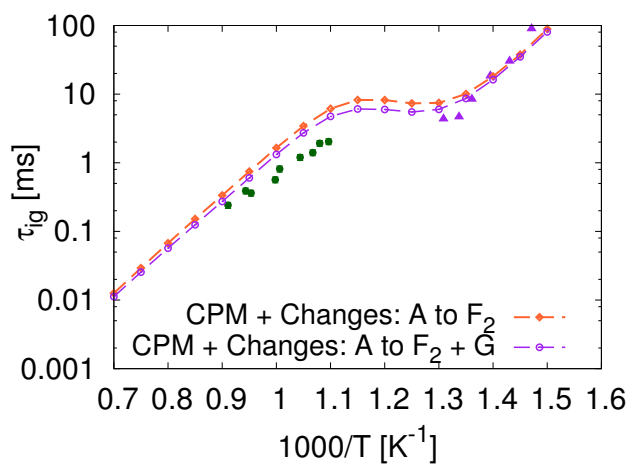

(g) Effect of Change G

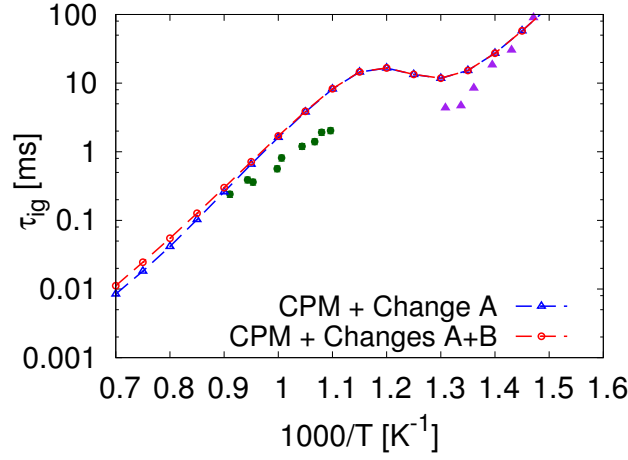

(b) Effect of Change B

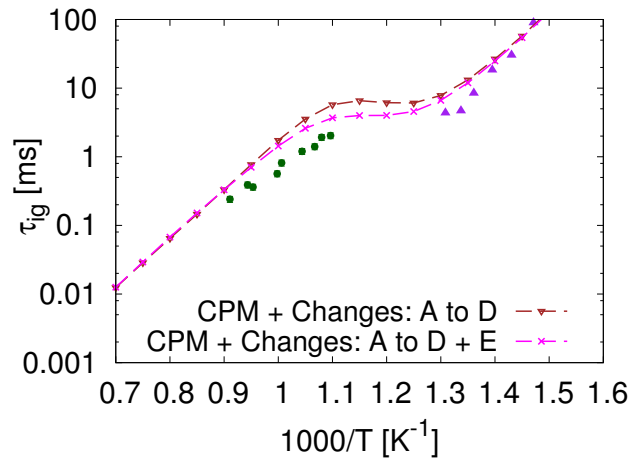

(e) Effect of Change E

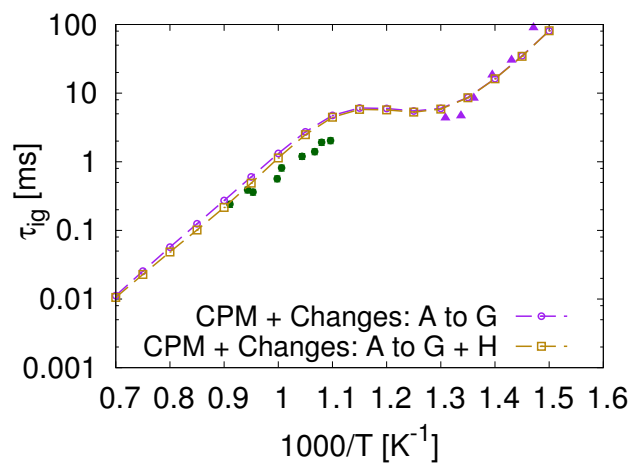

(h) Effect of Change $\mathrm{H}$

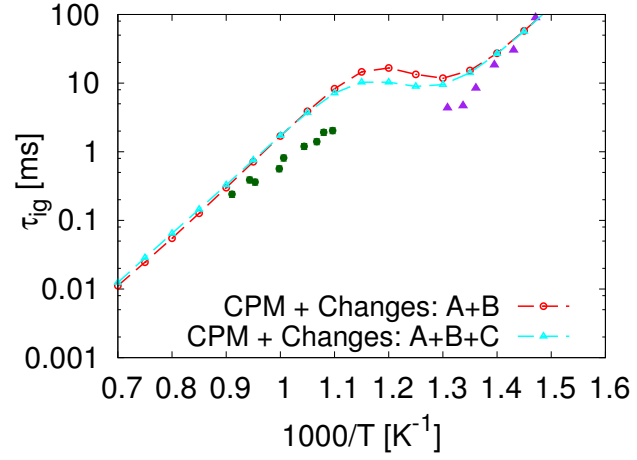

(c) Effect of Change C

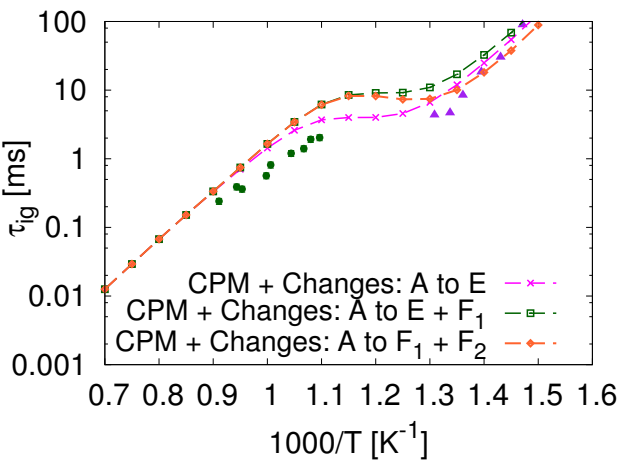

(f) Effect of Change $F_{1}, F_{2}$

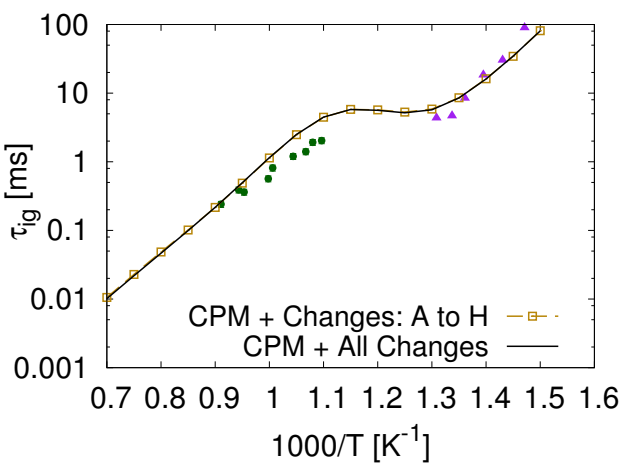

(i) Effect of Change I

Figure 6: Effect of different changes introduced to the CPM model on the ignition delays of stoichiometric methylcyclohexane/air mixtures at $P=20 \mathrm{~atm}$; symbols - experimental data: Vasu et al. 48, Pitz et al. 31; lines with points - simulations using reaction mechanisms at different stages of updates to the CPM model. (A) - isomerization of methylcyclohexane via ring opening, (B) - correction to the rate constant of $\mathrm{C}_{2} \mathrm{H}_{3}$ addition to the internal double bonded carbon in $\mathrm{C}_{3} \mathrm{H}_{6},(\mathrm{C})$ - ring opening of cyclohexylmethyl and methylcyclohexyl radicals, (D) - decomposition of $\gamma$-QOOH radicals, (E) - H-abstraction from cyclohexylmethyl by $\mathrm{O}_{2},\left(\mathrm{~F}_{1}\right)$ - introducing concerted elimination pathways, $\left(\mathrm{F}_{2}\right)$ - decomposition of ketohydroperoxide, $(\mathrm{G})$ - H-abstraction from methylcyclohexane, $(\mathrm{H})$ - alkenyl decomposition reactions, $(\mathrm{I})$ - benzene and toluene formation pathways. The results obtained using the updated reaction mechanism ( - in Fig. 6(i) show an improved agreement with the experimental data compared to the CPM model (-- - in Fig. 6(a) at all temperatures. 
E. H-abstraction from cyclohexylmethyl by $\mathrm{O}_{2}$ The detailed Pitz et al. 31 mechanism, and therefore the CPM model, has $\mathrm{H}$-abstraction reactions by $\mathrm{O}_{2}$ from different radicals of methylcyclohexane. The sensitivity analysis performed using the CPM model reveals that ignition delays in the NTC ignition regime, $780 \mathrm{~K}<T<900 \mathrm{~K}$, at $P=20 \mathrm{~atm}$, are highly impacted by the rate of $H$ abstraction from cyclohexylmethyl radical by $\mathrm{O}_{2}$ (highest sensitivity factor in Fig. 4(b)], given by,

$$
\mathrm{CYCHEXCH} 2+\mathrm{O}_{2} \rightarrow \mathrm{CHXDCH} 2+\mathrm{HO}_{2} \text {. }
$$

Nevertheless, from the understanding gained from alkane oxidation, such a reaction is expected to be important only at high temperatures, and not so much at those lower temperatures. In fact, Sarathy et al. 53. have not included this reaction class in their kinetic mechanism for methyl alkanes. This reaction class has been explored in our reaction mechanism for $n$-dodecane [23]. However, it was found to have little influence on the ignition delays, supporting the slow rates assigned to these reactions by Westbrook et al. [54 in their kinetic mechanism for normal alkanes.

In their detailed model, Pitz et al. 31] reduced the preexponential factors in the rate constants of $\mathrm{H}$-abstraction by $\mathrm{O}_{2}$ from the methylcyclohexyl radicals (MCHR1, MCHR2, MCHR3, and MCHR4),

$$
\begin{aligned}
& \mathrm{MCHR} 1+\mathrm{O}_{2} \rightarrow \mathrm{MCHE}+\mathrm{HO}_{2}, \\
& \mathrm{MCHR} 2+\mathrm{O}_{2} \rightarrow \mathrm{MCHE}+\mathrm{HO}_{2}, \text { etc. }
\end{aligned}
$$

by a factor of 100 from their original rate constants (the same rate constant is used for all reactions such as reactions (9) and (10) to allow these rates to be comparable to the rate of $\mathrm{H}$-abstraction from $n$-propyl radical by $\mathrm{O}_{2}$, while the original faster rate was used for reaction (8). In the present work, the pre-exponential factor used for the methylcyclohexyl radicals, such as in reaction (10), has also been assigned to reaction (8), resulting in a slower rate for this reaction. Figure 6(e) shows that the effect of this change is most felt in the ignition delays at temperatures, $780 \mathrm{~K}<T<1100 \mathrm{~K}$, leading to faster ignition at those temperatures.

F. Concerted elimination \& ketohydroperoxide decomposition Similar to point (E), the focus here is again on the formation of conjugate olefins in the low temperature oxidation of methylcyclohexane. The concerted elimination pathways involve the direct elimination of $\mathrm{HO}_{2}$ from peroxy radicals to form conjugate olefins. For cyclohexylmethyl peroxy radical and methylcyclohexyl peroxy radicals, these are given by

$$
\begin{aligned}
& \mathrm{CHXCH} 2 \mathrm{OO} \rightarrow \mathrm{CHXDCH} 2+\mathrm{HO}_{2}, \\
& \mathrm{MCH} 1 \mathrm{OO} \rightarrow \mathrm{CHXDCH} 2+\mathrm{HO}_{2}, \\
& \mathrm{MCH} 1 \mathrm{OO} \rightarrow \mathrm{MCHE}+\mathrm{HO}_{2}, \text { and } \\
& \mathrm{MCH} 2 \mathrm{OO} / \mathrm{MCH} 3 \mathrm{OO} / \mathrm{MCH} 4 \mathrm{OO} \rightarrow \mathrm{MCHE}+\mathrm{HO}_{2} .
\end{aligned}
$$

Recent studies [55-57] have highlighted the importance of these concerted elimination reactions. This was also noted by Pitz et al. 31, although these reactions were not included in their kinetic scheme. These pathways for cyclohexyl peroxy radicals have been considered in the cyclohexane mechanism proposed by Silke et al. [58] and found to be important for ignition delay predictions at temperatures $T<1000 \mathrm{~K}$.

In the present reaction mechanism, the concerted elimination pathways involving the cyclohexylmethyl peroxy radical and the methylcyclohexyl peroxy radicals have been introduced. The activation energies for reactions (11), $(12)$, and 13 are obtained from the quantum mechanical calculations performed at the CBS-QB3 level of theory by Yang et al. [59]. The activation energies for the reactions shown in (14) are taken to be the same as that for 13). In the absence of information on the pre-exponential factors corresponding to the calculations of Yang et al. [59], for reactions (13) and (14), the pre-exponential factor is taken to be $5 \times 10^{12} \mathrm{~s}^{-1}$, and half that value, i.e. $2.5 \times 10^{12} \mathrm{~s}^{-1}$, is used for reactions (11) and (12) to account for the number of possible routes for concerted elimination.

Note that the pre-exponential factor used for reactions 13 . and (14), equal to $5 \times 10^{12} \mathrm{~s}^{-1}$, falls between that calculated by Cavallotti et al. 60] for the direct $\mathrm{HO}_{2}$ elimination from the cyclohexyl peroxy radical $\left(7.7 \times 10^{12} \mathrm{~s}^{-1}\right)$, and that used by Silke et al. [58, for the same reaction $\left(3.85 \times 10^{12} \mathrm{~s}^{-1}\right)$. These choices lead to an overall good agreement with the ignition delays of methylcyclohexane in the NTC regime of ignition at higher pressures $(P \sim$ $50 \mathrm{~atm}$ ), as will be seen in the discussion in section 3.1.1. With this addition of the direct $\mathrm{HO}_{2}$ elimination pathways, the ignition delays at temperatures $T<1000 \mathrm{~K}$ increase, as seen from Fig. 6(f)] Further validation of the rate coefficients assigned to these concerted elimination pathways would require additional experimental data on the time evolution of alkenes in low temperature oxidation of methylcyclohexane.

At low temperatures, $T<800 \mathrm{~K}$, the ignition delays are largely influenced by the decomposition of methylcyclohexyl ketohydroperoxides. The rate constant assigned to this reaction class has been revisited in the present work. This reaction is now assigned a pre-exponential factor of $1 \times 10^{16} \mathrm{~s}^{-1}$, typically used for this reaction type $[53$, 61, 62, which is also consistent with that used in the $n$ dodecane sub-mechanism 23 in the present scheme, and an activation energy of $44 \mathrm{kcal} / \mathrm{mol}$. Figure 6(f) shows that the faster rate used for this reaction compared to the detailed Pitz et al. 31] model results in shorter ignition delays at low temperatures, bringing the simulations in better agreement with this experimental data. The activation energy of the ketohydroperoxide decomposition reaction prescribed here is comparable to the value of $42 \mathrm{kcal} / \mathrm{mol}$ used by Silke et al. 58 for the corresponding cyclohexyl ketohydroperoxide decomposition, while an even smaller activation energy of $39 \mathrm{kcal} / \mathrm{mol}$ is put forth in the recent modeling studies on alkane oxidation by Sarathy et al. 53 . 
and Mehl et al. 62 for this reaction type.

G. H-abstraction from methylcyclohexane Ignition delay predictions at moderate and high temperatures are sensitive to the rates of $\mathrm{H}$-abstraction from the fuel, methylcyclohexane, by different radicals $\mathrm{H}, \mathrm{OH}, \mathrm{HO}_{2}$, and $\mathrm{CH}_{3} \mathrm{O}_{2}$ (see Fig. 4). These rate constants have been revisited in the present work. Specifically, the rate constants used in the detailed mechanism of Pitz et al. 31 for the $\mathrm{H}$-abstraction from methylcyclohexane by $\mathrm{HO}_{2}$ and $\mathrm{CH}_{3} \mathrm{O}_{2}$, based on the rate rules then prescribed by Curran et al. [61, have been updated according to the recent rate rules suggested by Sarathy et al. 53.

For the reactions involving the secondary $\mathrm{H}$-abstraction by $\mathrm{H}$ atom from methylcyclohexane, the rate parameters have been updated based on the rate expressions derived experimentally by Peukert et al. 63] for the H-abstraction from cyclohexane by $\mathrm{H}$ atom. The abstraction reactions leading to MCHR2, MCHR3, and MCHR4 radicals in the products have been assigned a rate that is $4 / 12,4 / 12$, and $2 / 12$ of that reported in Peukert et al. 63, accounting for the number of abstractable $\mathrm{H}$ atoms. The rate constants of $\mathrm{H}$-abstraction by $\mathrm{OH}$ have been updated based on the theoretical calculations and experimental measurements of these rate constants by Sivaramakrishnan and Michael 64].

Upon incorporating these rate changes, the ignition delays decrease for $T>700 \mathrm{~K}$, as noted in Fig. 6(g). A big part of that difference at high temperatures comes from the modification to the rate of $\mathrm{H}$-abstraction from the fuel by $\mathrm{H}$ atom, $\mathrm{HO}_{2}$, and $\mathrm{CH}_{3} \mathrm{O}_{2}$ radicals. At temperatures $T<1000 \mathrm{~K}$, the revisions to the rate of $\mathrm{H}$-abstraction by $\mathrm{OH}$ radical also contribute to the shorter ignition delays, apart from the changes to the abstraction by $\mathrm{HO}_{2}$ and $\mathrm{CH}_{3} \mathrm{O}_{2}$ radicals.

H. Decomposition reactions The rate coefficients for the decomposition of the resonance stabilized linear hexadienyl radical, represented in the mechanism as the

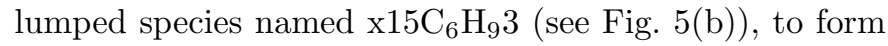
vinyl and butadiene,

$$
\mathrm{x} 15 \mathrm{C}_{6} \mathrm{H}_{9} 3 \rightarrow \mathrm{C}_{2} \mathrm{H}_{3}+\mathrm{C}_{4} \mathrm{H}_{6}
$$

have been updated from the quantum chemical calculations of Cavallotti et al. 65. The rate constant for the addition of tertiary $\mathrm{C}_{3} \mathrm{H}_{5}$ radical to ethylene,

$$
\mathrm{T}-\mathrm{C}_{3} \mathrm{H}_{5}+\mathrm{C}_{2} \mathrm{H}_{4} \rightleftharpoons \mathrm{aC}_{5} \mathrm{H}_{9} \mathrm{~d},
$$

is updated to that of the addition of $\mathrm{C}_{2} \mathrm{H}_{3}$ with $\mathrm{C}_{2} \mathrm{H}_{4}$ used in the base model [1, a change justified by the similar nature of the radicals that add to the $\mathrm{C}=\mathrm{C}$ bond in ethylene. These changes were found to be important at high temperatures, resulting in slightly faster ignition (see Fig. 6(h) and earlier rise in $\mathrm{OH}$ profiles (not shown here), and improving the agreement with the experimental data.
In addition, the rate of decomposition of methylcyclohexane to give methyl radical and cyclohexyl radical is taken from the rates calculated recently by Zhang et al. 50]. Further, the decomposition of cyclohexene to give ethylene and butadiene and the formation of benzene and $\mathrm{H}_{2}$ from 1,3-cyclohexadiene are updated as per Silke et al. [58. The same rate constant is also used for the decomposition of methylcyclohexene to give ethylene and isoprene. These changes did not result in a significant difference to the ignition delays shown by brown lines in Fig. 6(h)

I. Benzene and toluene formation pathways The reaction pathways for the formation of benzene and toluene via successive loss of $\mathrm{H}$ atoms from cyclohexyl and methylcyclohexyl radicals respectively, described in the reference Pitz et al. mechanism, are retained in the present mechanism. These pathways have also been investigated in other studies, Refs. [27, 33, 40, 66, for instance. In the present work, the rates of some reactions in these dehydrogenation pathways have been revisited.

In the formation of toluene, the methylcyclohexyl radical loses an $\mathrm{H}$ atom first forming methylcyclohexene. Upon $\mathrm{H}$ atom abstraction by radicals (primarily $\mathrm{H}$ and $\mathrm{OH}$ ), methylcyclohexene forms the methylcyclohexenyl radical. This radical further loses an $\mathrm{H}$ atom to form methylcyclohexadiene, or it undergoes a ring opening to form the linear heptadienyl radical. Further, methylcyclohexadiene upon $\mathrm{H}$ atom abstraction forms the corresponding radical, which loses an $\mathrm{H}$ atom to give toluene. This sequence is described in Fig. 7. Similarly, starting with cyclohexyl radical, a sequence of $H$ atom elimination and $H$ atom abstraction explains the formation of benzene.

In the present work, the rate constants for $\mathrm{H}$ elimination reactions from (i) cyclohexyl radical are updated from the quantum chemical calculations of Sirjean et al. 52, (ii) methylcyclohexyl radical are derived from those for cyclohexyl radical, accounting for the number of $\mathrm{H}$ atoms available for abstraction. The reaction rate constants for $\mathrm{H}$ atom abstraction by $\mathrm{H}$ and $\mathrm{OH}$ radicals from 1,3-cyclohexadiene, methylcyclohexene, and methylcyclohexadiene have been taken from analogous reactions of 1-butene in the base mechanism. The rate coefficients for $\mathrm{H}$ elimination reactions from the resonantly stabilized cyclohexenyl radical ( $\mathrm{CYCC}_{6} \mathrm{H}_{9} 1$, see Fig. 5(g) comes from the detailed Pitz et al. 31. model, and the same is also used for $\mathrm{H}$ elimination from methylcyclohexenyl radical, which represents the resonantly stabilized isomers of that radical. Note that these rate constants are comparable to those of $\mathrm{H}$ elimination from 1-bute-3-nyl radical, which is again a resonantly stabilized radical.

The rate coefficients for ring closing reactions of linear hexadienyl radicals to form cyclohexenyl radical $\mathrm{CYCC}_{6} \mathrm{H}_{9} 1$, which is resonance stabilized, and $\mathrm{CYCC}_{6} \mathrm{H}_{9} 2$, which is not resonance stabilized, have been adopted from those of the cyclohexyl radical [52] and the rate coefficients for 


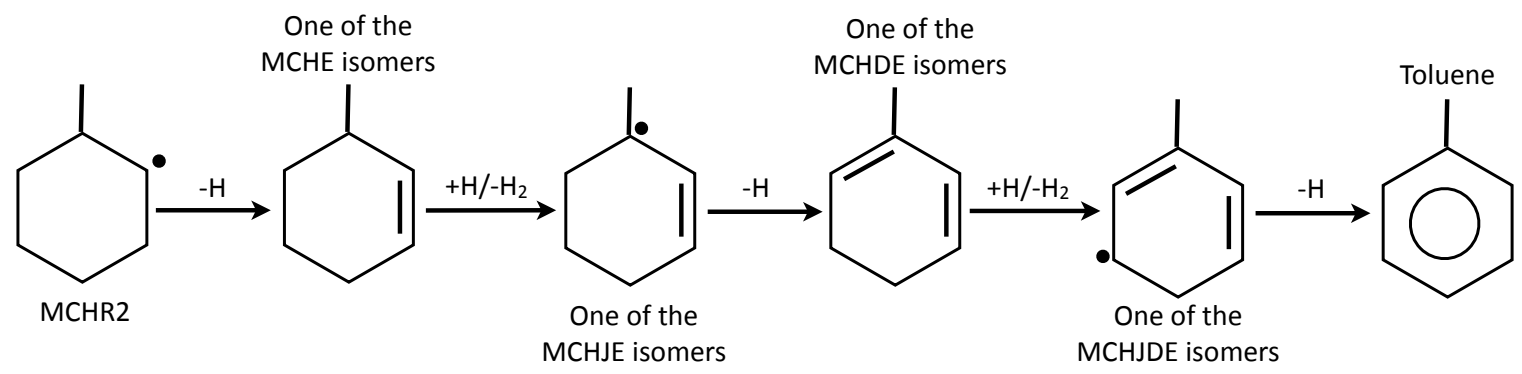

Figure 7: Formation of toluene via successive loss of $\mathrm{H}$ atoms from methylcyclohexyl radicals. Only a representative pathway starting with 2-methylcyclohexyl radical (MCHR2) is shown here. Full species names: (i) MCHE - methylcyclohexene, (ii) MCHJE - methylcyclohexenyl radical, (iii) MCHDE - methylcyclohexadiene, (iv) MCHJDE - methylcyclohexadienyl radical.

the reverse reaction are obtained from thermochemistry. For the reaction where the lumped resonantly stabilized linear hexadienyl radical $\left(\mathrm{x} 15 \mathrm{C}_{6} \mathrm{H}_{9} 3\right.$, see Fig. $5(\mathrm{~b})$ forms $\mathrm{CYCC}_{6} \mathrm{H}_{9} 2$, the distribution of the individual isomers calculated from the reference Pitz et al. 31 mechanism is taken into account in arriving at the ring closing and opening rates. Note that the pathways for radical addition $(\mathrm{H}$, $\mathrm{CH}_{3}$ ) on the resonantly stabilized linear hexadienyl radical have an insignificant impact on the kinetics of that molecule, and have therefore been removed from the mechanism during reduction.

The ring opening/closure rate coefficients of methylcyclohexenyl radical are taken to be the same as those for the resonantly stabilized cyclohexenyl radical. The ring opening product of methylcyclohexenyl radical, taken entirely to be 1,3-heptadien-6-yl $\left(\mathrm{x}_{13} \mathrm{C}_{7} \mathrm{H}_{11} 6\right.$, see Fig. 5(b) radical, loses an $\mathrm{H}$-atom to form 1,3,5-heptatriene, which further adds an $\mathrm{H}$-atom to form the resonantly stabilized 1,5-heptadien-4-yl (x15 $\left.\mathrm{C}_{7} \mathrm{H}_{11} 4\right)$ radical. The rate constant for the decomposition of this linear heptadienyl radical to give vinyl radical and 1,3-pentadiene are taken to be the same as that of reaction (15) for the analogous linear hexadienyl radical. While these modifications make little difference to the ignition delays (see Fig. 6(i), they are important to predict the aromatics found in the oxidation of methylcyclohexane, as evidenced by the results for speciation in premixed flames presented in section 3.5 .

Overall, the ignition delays computed using the final revised mechanism ( - in Fig. 6(i) show improved agreement with the experimental data compared to the CPM model (-- - in Fig. 6(a) at all temperatures.

Note that the changes described in this section have been introduced in the incremental methylcyclohexane reaction set, with no change to the base model. The validation tests for the potential surrogate fuel components investigated previously [1, 4, 23, viz. $n$-heptane, iso-octane, toluene, ethylbenzene, styrene, $\alpha$-methyl naphthalene, $m$ xylene, and $n$-dodecane have been repeated using the present reaction mechanism and made available as part of the Supporting materials (Figs. S16-S33).

This reaction mechanism, which now describes the low to high temperature oxidation of methylcyclohexane, in addition to the fuels validated in our previous works [1, 4, 23], consists of 369 species and 2691 reactions counted forward and reverse separately. The mechanism files in Chemkin and FlameMaster format can be obtained from the Supporting materials. The sources for the reaction rate constants in the kinetic scheme are provided in the mechanism file in FlameMaster format. A list of the individual isomers represented by each of the lumped species present in the methylcyclohexane sub-mechanism is also provided in the Supporting materials (Tables S1-S3).

The thermodynamic and transport properties for the proposed reaction mechanism have also been provided with the Supporting materials, with references to their sources. The parameters for the species already present in base + aromatics + dodecane model remain unchanged from those in Ref. 23. For the new species added to this model, belonging to the incremental methylcyclohexane reaction set, these properties have been taken from Pitz et al. 31]. This approach remains valid for the lumped species in the reaction mechanism as well, since only chemical isomers have been lumped together in the reduction process, which typically have similar thermodynamic and transport properties [4].

\section{Validation tests}

This section evaluates the ability of the revised mechanism to predict different targets of interest to methylcyclohexane oxidation by comparing simulations against a large experimental database. The validation tests focus on oxidation environments and include (i) ignition delays spanning wide ranges of temperatures, pressures, and equivalence ratios (ii) species time histories measured in shock tubes, (iii) concentration profiles of fuel, major intermediates, and products, measured in a flow reactor at high temperatures, (iv) laminar flame speeds obtained at different pressures, and (v) detailed species measurements in premixed flames at low pressures. The list of the validation tests, which are discussed in further detail below, appears in Table 1. 
Shock tube experiments are modeled using a constant volume homogeneous reactor configuration. The same ignition criterion as in the experiments is used to compute the ignition delay times. Constant pressure simulations under adiabatic conditions are used to model the flow reactor experiments. Laminar speeds have been calculated in a manner similar to that described in our previous works [1. 4, 23. The simulation results discussed in this section have been computed using the present reaction mechanism, as it stands at the end of section 2.3. unless stated otherwise. All numerical calculations have been performed using the FlameMaster code (version 3.3.9, 67]).

In addition to the test cases listed in Table 1, the simulations have also been compared against (a) species concentrations in a pyrolysis experiment [29], and (b) species profiles measured in low pressure premixed flames [40] (Figs. S5, S12, S13 in the Supporting materials), while leaving out other configurations in which kinetics are strongly coupled with diffusion, such as counterflow diffusion flame experiments, as the focus of the present work is mainly on the kinetics aspect. Further, mixtures of methylcyclohexane with toluene and $n$-dodecane have been tested against experiments for species profiles in oxidation and laminar flame speeds. These results have been provided with the Supporting materials (Figs. S14 and S15) for the sake of reference.

\subsection{Ignition delays}

\subsubsection{Methylcyclohexane/air ignition delays}

The ignition delays computed using the proposed kinetic scheme are compared in Fig. 8 against the experimental data measured in shock tubes by Vasu et al. [48] and Vanderover and Oehlschlaeger [68] at stoichiometric conditions, spanning a wide range of pressures, $P=12,20,45$, and $50 \mathrm{~atm}$, and temperatures above $750 \mathrm{~K}$. Also shown in this figure are comparisons against ignition delay times measured in a Rapid Compression Machine (RCM) study by Pitz et al. 31. at $\phi=1.0$ and $P=15,20$ atm. Both shock tube and RCM experiments are modeled using a constant volume, adiabatic, homogenous configuration, an approach also taken by Pitz et al. in their work 31. Note that in the RCM case, heat losses have been accounted for in the calculation of the compressed temperature, $T_{c}$ [31.

Overall, a good agreement is obtained for ignition delay times between the present scheme and the experimental data in Fig. 8 for low through high temperatures as a result of the changes discussed in section 2.3. The mechanism captures the pressure dependence of the ignition delays exhibited by the experimental data at both high and low temperatures in Figs. 8(a) and 8(b). The computed ignition delays at $900<T<1000 \mathrm{~K}$ at $P=20 \mathrm{~atm}$ are longer than the experimental data in Fig. 8(b) but show better agreement at higher pressures $(P=45 \mathrm{~atm})$. The slope of ignition delays at intermediate temperatures and $P=45 \mathrm{~atm}$ is also well represented by the simulations.

The simulated results are compared against ignition delay times measured at lean conditions, $\phi=0.25$ and
0.5, by Vanderover and Oehlschlaeger 68 in Fig. 9. The simulations are able to capture the change in ignition delays at lean fuel conditions and at different pressures. The predictions at $\phi=0.5$ in Fig. 9(a) show good agreement with the experimental data at all temperatures of interest here, and fall within the uncertainties in the measurements. While the simulations at high temperatures and $\phi=0.25$ in Fig. 9(b) are in accordance with the experiments, the computed results do not show the inflection suggested by the experimental data points at $T \lesssim 1000 \mathrm{~K}$ and $P=50 \mathrm{~atm}$. A pressure dependent treatment for the $\mathrm{R}+\mathrm{O}_{2}$ pathways could be important to correct the over prediction of ignition delays in the NTC ignition regime in Figs. 8(b) and 9(b).

\section{Sensitivity analysis}

A sensitivity analysis is performed using the present reaction mechanism at $\phi=1$ and $P=20$ atm to identify the important pathways for ignition delay predictions at different temperatures. Sensitivity coefficients are determined here by doubling each rate constant and finding the relative change in ignition delays due to the rate change. Hence, reactions showing positive sensitivity factors increase ignition delays, and those showing negative sensitivity coefficients result in faster ignition.

High temperature ignition. The result of the sensitivity study at $T=1250 \mathrm{~K}$ is presented in Fig. 10(a) The importance of reactions involving $\mathrm{H}$-abstraction reactions by $\mathrm{OH}, \mathrm{O}$, and $\mathrm{H}$ from the fuel, methylcyclohexane, is evident from this chart. The ignition delays are also sensitive to the decomposition of methylcyclohexane into methyl radical and cyclohexyl radical. It is interesting to note that the sensitivity factors for the $\mathrm{H}$-abstraction reactions by $\mathrm{OH}, \mathrm{H}$, and $\mathrm{O}$ show negative factors for reactions forming MCHR4 radicals, while they show positive factors for reactions forming $\mathrm{MCHR} 2, \mathrm{MCHR} 3$, and $\mathrm{CYCHEXCH} 2$ radicals. This observation is directly related to the importance of vinyl radicals $\left(\mathrm{C}_{2} \mathrm{H}_{3}\right)$ at these high temperatures, which was also noted by Orme et al. [30].

In order to understand this, a reaction flux analysis was conducted for the conditions of interest here. The basis for the analysis are the integrated production and consumption rates for the species present in the reaction mechanism for a time $t=20 \mu \mathrm{s}$, at which $30 \%$ of the fuel has been consumed. The consumption pathways of methylcyclohexyl radicals MCHR4 and MCHR2 are traced from the reaction flux analysis in the following discussion.

Consumption pathways of MCHR4 radical: At these conditions, the MCHR4 radical ring opens, and almost entirely forms $\mathrm{eC}_{7} \mathrm{H}_{13} \mathrm{a}$, which further decomposes completely to give $\mathrm{C}_{4} \mathrm{H}_{7}$ radicals as

$$
\mathrm{eC}_{7} \mathrm{H}_{13} \mathrm{a} \rightarrow \mathrm{C}_{4} \mathrm{H}_{7}+\mathrm{C}_{3} \mathrm{H}_{6} .
$$




\begin{tabular}{|c|c|c|c|c|}
\hline \multicolumn{2}{|c|}{ Shock tubes } & \multirow{2}{*}{ Plug Flow Reactor } & \multicolumn{2}{|c|}{ Premixed flames } \\
\hline Ignition delays & Species profiles & & Laminar flame speed & Detailed species profiles \\
\hline $\begin{array}{c}\text { Vanderover et al. }[68] \\
\text { Vasu et al. }[48 \\
\text { Pitz et al. } 31] \\
\text { Hong et al. } 335] \\
\text { Orme et al. } 30\end{array}$ & $\begin{array}{l}\text { Vasu et al. }[49 \\
\text { Hong et al. } 35\end{array}$ & Zeppieri et al. [29] & $\begin{array}{l}\text { Kumar et al. } 36] \\
\text { Singh et al. }[37] \\
\text { Ji et al. } 38] \\
\text { Kelley et al. } 39]\end{array}$ & Wang et al. [33, 69, \\
\hline
\end{tabular}

Table 1: Validation cases for methylcyclohexane considered in the present study.

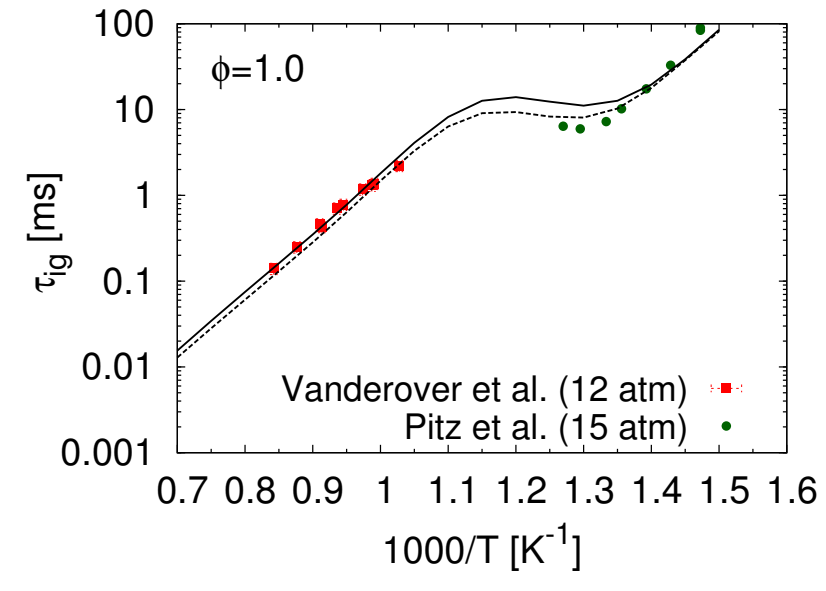

(a) $\phi=1.0, P=12,15 \mathrm{~atm}$

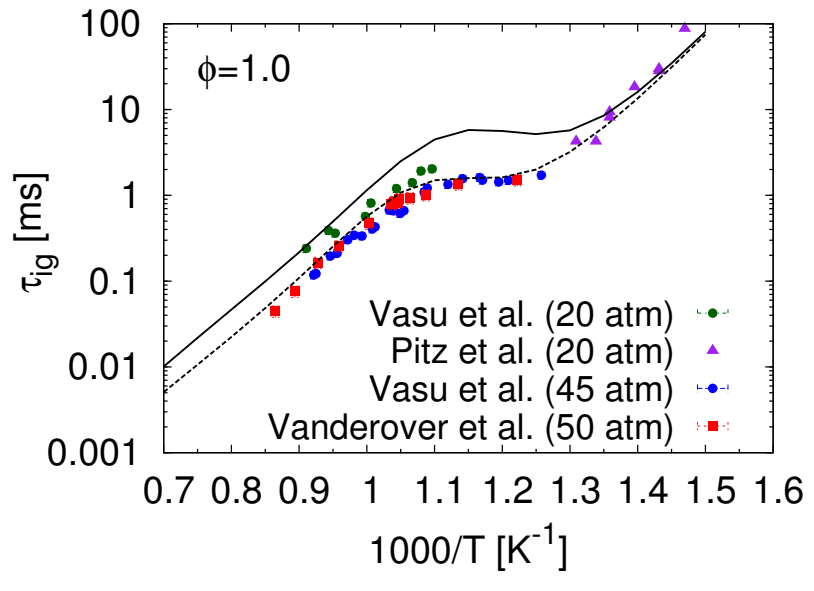

(b) $\phi=1.0, P=20,45 \mathrm{~atm}$

Figure 8: Ignition delay times of methylcyclohexane/air mixtures; symbols - experimental data from Vanderover and Oehlschlaeger [68, Pitz et al. [31], Vasu et al. [48; lines - simulations (using the present reaction mechanism); solid lines - lower pressure, dashed lines - higher pressure.

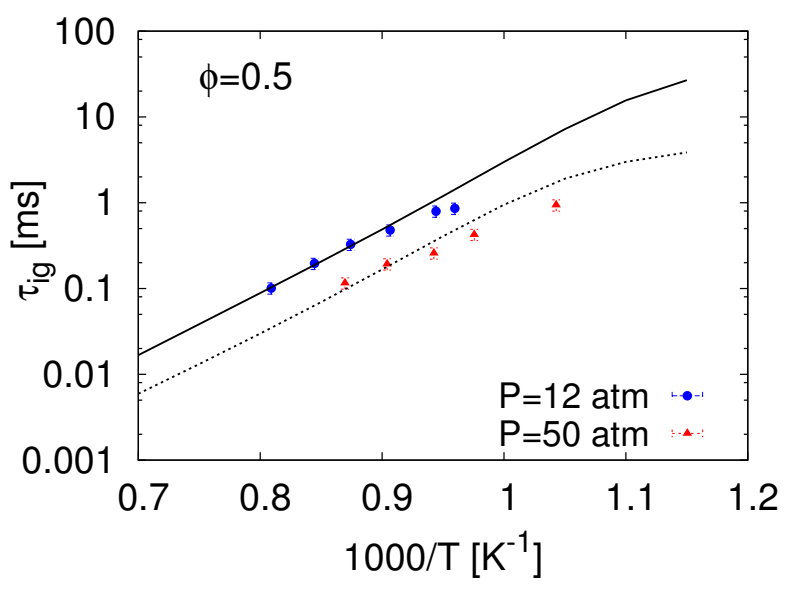

(a) $\phi=0.5, P=12,50 \mathrm{~atm}$

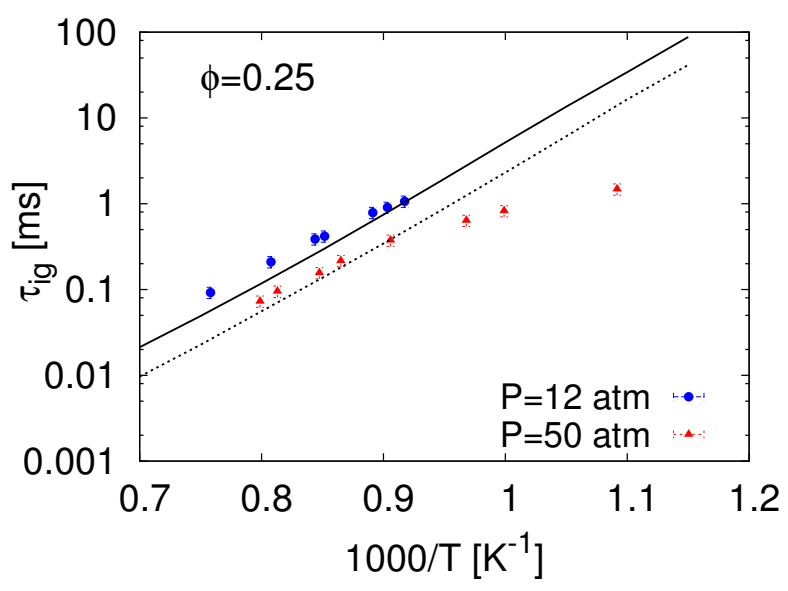

(b) $\phi=0.25, P=12,50 \mathrm{~atm}$

Figure 9: Ignition delay times of methylcyclohexane/air mixtures; symbols - experimental data from Vanderover and Oehlschlaeger 68]; lines - simulations (using the present reaction scheme); solid lines - lower pressure, dashed lines - higher pressure. 


$$
\begin{array}{r}
\mathrm{MCH}+\mathrm{OH}->\mathrm{MCHR} 4+\mathrm{H} 2 \mathrm{O} \\
\mathrm{MCH}+\mathrm{OH}->\mathrm{MCHR} 3+\mathrm{H} 2 \mathrm{O} \\
\mathrm{MCH}+\mathrm{OH}->\mathrm{MCHR} 2+\mathrm{H} 2 \mathrm{O} \\
\mathrm{MCH}+\mathrm{O}->\mathrm{MCHR} 4+\mathrm{OH} \\
\mathrm{MCH}+\mathrm{H}->\mathrm{CYCHEXCH} 2+\mathrm{H} 2 \\
\mathrm{MCH}+\mathrm{OH}->\mathrm{CYCHEXCH} 2+\mathrm{H} 2 \mathrm{O} \\
\mathrm{MCH}+\mathrm{H}->\mathrm{MCHR} 3+\mathrm{H} 2 \\
\mathrm{MCH}+\mathrm{H}->\mathrm{MCHR} 1+\mathrm{H} 2 \\
\mathrm{MCH}+\mathrm{H}->\mathrm{MCHR} 2+\mathrm{H} 2 \\
\mathrm{CC} 5 \mathrm{H} 9 \mathrm{~A}->\mathrm{C} 3 \mathrm{H} 6+\mathrm{C} 2 \mathrm{H} 3 \\
\mathrm{MCH}+\mathrm{H}->\mathrm{MCHR} 4+\mathrm{H} 2 \\
\mathrm{MCH}-\mathrm{CH} 3+\mathrm{CYCHEXRAD}
\end{array}
$$

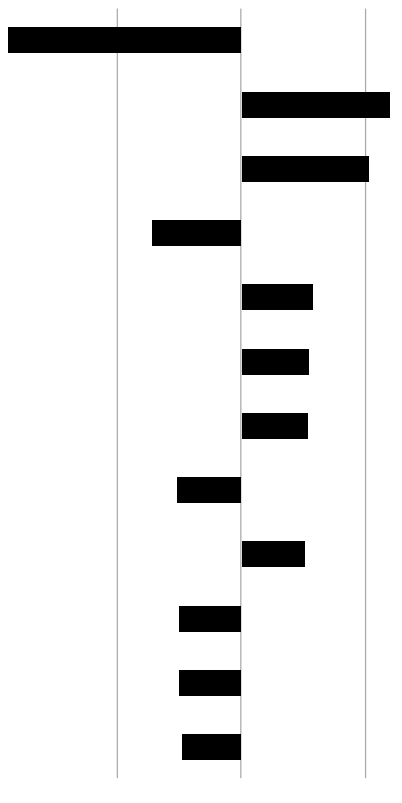

(a) $\mathrm{T}=1250 \mathrm{~K}$

0.1

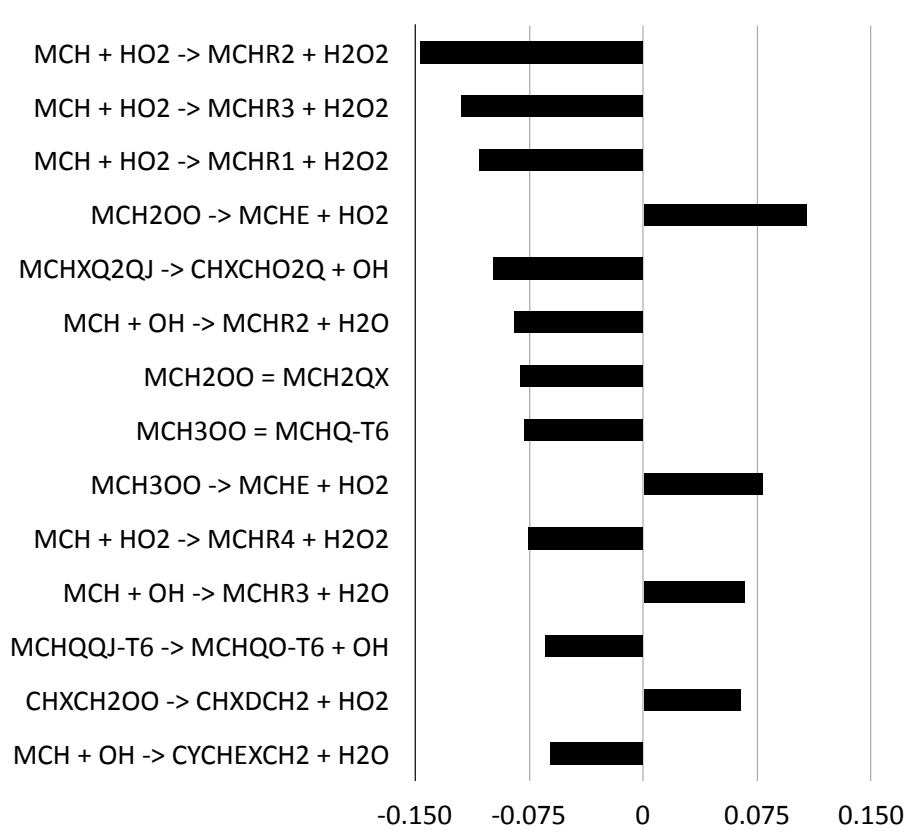

(b) $T=909 \mathrm{~K}$

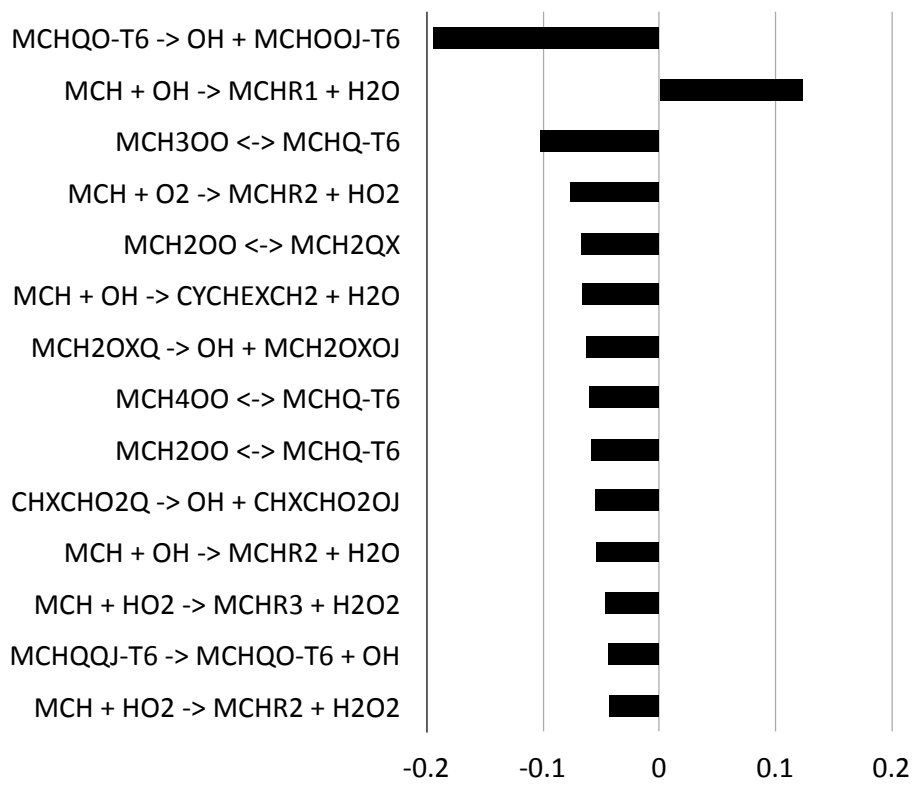

(d) $T=660 \mathrm{~K}$

$$
\begin{array}{r}
\mathrm{MCHQ}-\mathrm{T} 6->\mathrm{MCHYO} 24+\mathrm{OH} \\
\mathrm{MCH}+\mathrm{OH}->\mathrm{MCHR} 2+\mathrm{H} 2 \mathrm{O} \\
\mathrm{MCHQQJ}-\mathrm{T} 6->\mathrm{MCHQO}-\mathrm{T} 6+\mathrm{OH} \\
\mathrm{MCH} 2 \mathrm{OO}->\mathrm{MCHE}+\mathrm{HO} 2 \\
\mathrm{MCH}+\mathrm{OH}->\mathrm{CYCHEXCH} 2+\mathrm{H} 2 \mathrm{O} \\
\mathrm{MCH}+\mathrm{OH}->\mathrm{MCHR} 1+\mathrm{H} 2 \mathrm{O} \\
\mathrm{MCH} 3 \mathrm{OO}->\mathrm{MCHE}+\mathrm{HO} 2 \\
\mathrm{MCH} 2 \mathrm{OO}=\mathrm{MCH} 2 \mathrm{OX} \\
\mathrm{MCHE}+\mathrm{OH}->\mathrm{MCHJE}+\mathrm{H} 2 \mathrm{O} \\
\mathrm{MCH} 3 \mathrm{OO}=\mathrm{MCHQ}-\mathrm{T} 6 \\
\mathrm{MCHQO}-\mathrm{T} 6->\mathrm{OH}+\mathrm{MCHOOJ}-\mathrm{T} 6 \\
\mathrm{MCH} 4 \mathrm{OO}->\mathrm{MCHE}+\mathrm{HO} 2 \\
\mathrm{MCH} 3 \mathrm{OO}->\mathrm{MCHQ}-\mathrm{T5S} \\
\mathrm{MCH} 2 \mathrm{OO}->\mathrm{MCH} 2 \mathrm{OJ} 1
\end{array}
$$

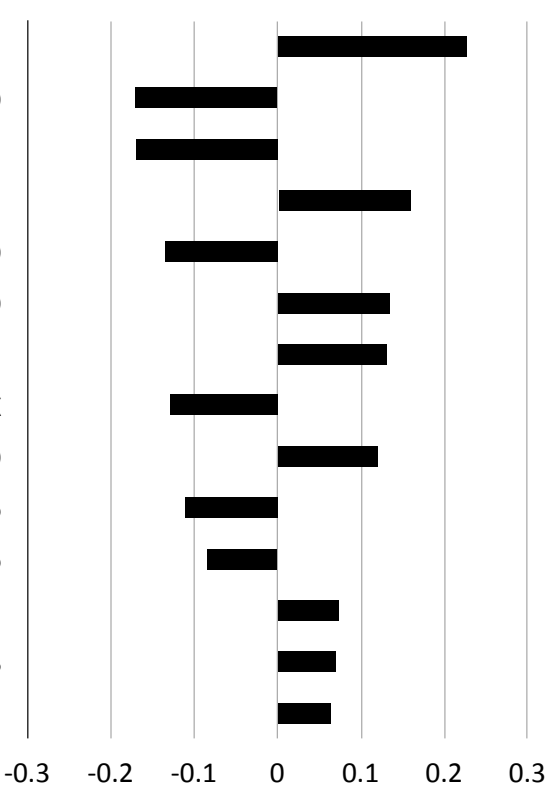

(c) $T=769 \mathrm{~K}$

Figure 10: Sensitivity analysis for ignition delays of methylcyclohexane/air mixtures at $\phi=1.0$ and $P=20$ atm using the present reaction mechanism, as it stands at the end of section 2.3 Sensitivities are determined by multiplying each rate constant by a factor of 2 , and finding the change in ignition delays due to the rate change. Only reactions in the incremental MCH mechanism with sensitivity factor $\geq 5 \%$ are reported here. The non-lumped species names are similar to those used in the original Pitz et al. 31] mechanism. Refer to Tables S1-S3 in the supplementary materials for a description of the generic names used for the lumped species in this figure. 
The $\mathrm{C}_{4} \mathrm{H}_{7}$ radicals have two main decomposition pathways,

$$
\begin{aligned}
\mathrm{C}_{4} \mathrm{H}_{7} & \rightarrow \mathrm{C}_{4} \mathrm{H}_{6}+\mathrm{H}, \text { and } \\
& \rightarrow \mathrm{C}_{2} \mathrm{H}_{3}+\mathrm{C}_{2} \mathrm{H}_{4},
\end{aligned}
$$

where almost $77 \%$ of the $\mathrm{C}_{4} \mathrm{H}_{7}$ radicals proceed to form the highly reactive vinyl radical, $\mathrm{C}_{2} \mathrm{H}_{3}$, according to reaction 19, and the rest forms $\mathrm{H}$ atoms according to reaction (18). The vinyl radicals form $\mathrm{CH}_{2} \mathrm{CHO}$ by the addition of an $\mathrm{O}_{2}$ molecule (rate constant from Mebel et al. 70]), as

$$
\mathrm{C}_{2} \mathrm{H}_{3}+\mathrm{O}_{2} \rightleftharpoons \mathrm{CH}_{2} \mathrm{CHO}+\mathrm{O} \text {. }
$$

Subsequently, $\mathrm{HCO}$ is formed from $\mathrm{CH}_{2} \mathrm{CHO}$ by the addition of an $\mathrm{O}_{2}$ molecule, and the formyl radicals predominantly lead to $\mathrm{HO}_{2}(\sim 87 \%$ at these conditions $)$, which is an important species for high temperature ignition, vital for the formation of $\mathrm{OH}$ radicals.

Consumption pathways of MCHR2 radical: On the other hand, MCHR2 radicals decompose through two major routes, given by,

$$
\begin{aligned}
\mathrm{MCHR} 2 & \rightleftharpoons \mathrm{gC}_{7} \mathrm{H}_{13} \mathrm{l}, \\
& \rightarrow \mathrm{CYCHEXENE}+\mathrm{CH}_{3},
\end{aligned}
$$

where almost $60 \%$ proceeds via the second reaction 22 and $30 \%$ via reaction (21).

Following reaction (21), $\mathrm{gC}_{7} \mathrm{H}_{13} \mathrm{l}$ radicals mainly $(\sim$ $75 \%$ ) decompose further to give $\mathrm{cC}_{5} \mathrm{H}_{9}$ radicals, according to

$$
\mathrm{gC}_{7} \mathrm{H}_{13} \mathrm{l} \rightarrow \mathrm{cC}_{5} \mathrm{H}_{9} \mathrm{a}+\mathrm{C}_{2} \mathrm{H}_{4} \text {. }
$$

The $\mathrm{c}_{5} \mathrm{H}_{9}$ a radicals previously encountered in section 2.3 . break up further according to the reactions

$$
\begin{aligned}
\mathrm{cC}_{5} \mathrm{H}_{9} \mathrm{a} & \rightleftharpoons \mathrm{C}_{4} \mathrm{H}_{6}+\mathrm{CH}_{3}, \\
& \rightleftharpoons \mathrm{C}_{2} \mathrm{H}_{3}+\mathrm{C}_{3} \mathrm{H}_{6},
\end{aligned}
$$

where almost $86 \%$ of the $\mathrm{cC}_{5} \mathrm{H}_{9}$ a radicals proceed to form butadiene, $\mathrm{C}_{4} \mathrm{H}_{6}$, according to reaction (24), and the rest (only about 13\%) form vinyl radicals according to reaction (25). As noted previously, since highly reactive vinyl radicals are formed as a result of this reaction, the negative sensitivity factor shown by reaction 25 towards ignition delays in Fig. 10(a), is certainly justified.

Following the pathway shown in reaction 22, cyclohexene is mainly consumed via $\mathrm{H}$-abstraction reactions by $\mathrm{H}, \mathrm{O}$, and $\mathrm{OH}$ radicals to form the resonantly stabilized $(\sim 47 \%)$ and non-resonance stabilized $(\sim 29 \%)$ cyclohexenyl radicals (see Fig. 5(g)). The non-resonance stabilized cyclohexenyl radical $\left(\mathrm{CYCC}_{6} \mathrm{H}_{9} 2\right)$ upon ring opening forms the linear hexadienyl radical entirely, which further forms vinyl radicals according to reaction (15). The resonantly stabilized cyclohexenyl radical $\left(\mathrm{CYCC}_{6} \mathrm{H}_{9} 1\right)$ forms 1,3-cyclohexadiene $(\sim 60 \%)$ by $\mathrm{H}$ atom removal, and gives

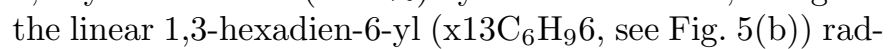
ical via a ring-opening pathway $(\sim 40 \%)$, as

$$
\begin{aligned}
\mathrm{CYCC}_{6} \mathrm{H}_{9} 1 & \rightleftharpoons 1,3 \text {-cyclohexadiene }+\mathrm{H}, \\
& \rightleftharpoons \mathrm{x}_{13} \mathrm{C}_{6} \mathrm{H}_{9} 6 .
\end{aligned}
$$

Through a 1,3,5-hexatriene intermediate, about $55 \%$ of the 1,3-hexadien-6-yl radical leads to the resonantly stabilized linear hexadienyl radical $\left(\mathrm{x}_{15} \mathrm{C}_{6} \mathrm{H}_{9} 3\right.$, see Fig. $5(\mathrm{~b})$, which gives vinyl radicals according to reaction (15), and the rest reacts via a $\beta$-scission to give ethylene and $n-\mathrm{C}_{4} \mathrm{H}_{5}$. The 1,3-cyclohexadiene formed in reaction 26 gives the cyclohexadienyl radical through abstraction of an $\mathrm{H}$ atom by $\mathrm{H}$ and $\mathrm{OH}$ radicals, which further leads to benzene, as explained in section 2.3 .

From this discussion, it is evident that the decay channels of MCHR2 result in a significantly smaller amount of vinyl radicals compared to MCHR4, due to competing pathways (reaction (24) for instance). Also note that $\mathrm{H}$ atoms, which are important for the branching step $\mathrm{H}+$ $\mathrm{O}_{2} \rightleftharpoons \mathrm{O}+\mathrm{OH}$, are produced from MCHR4 via reaction (18), while less reactive $\mathrm{CH}_{3}$ radicals are produced from MCHR2 (reaction (22)). An analysis, similar to that for MCHR2 radicals, also holds for MCHR3 and CYCHEXCH2 radicals, when their decay pathways are considered. This explains the higher reactivity (corresponding to a negative sensitivity factor and shorter ignition delays), when the branching ratio of methylcyclohexane consumed via $\mathrm{H}-$ abstraction reactions to form MCHR4 radicals is increased compared to the other methylcyclohexyl radicals.

Moderate and low temperature ignition. The importance of different reactions to ignition delays at $\phi=1, P=$ $20 \mathrm{~atm}$, and $T \sim 900 \mathrm{~K}$, the temperature at which the ignition regime transitions from the NTC regime to high temperature ignition, is summarized in Fig. 10(b). At these temperatures, the $\mathrm{H}$-abstraction reactions by $\mathrm{HO}_{2}$ from the fuel become more important to predict ignition delays. The large positive sensitivity factors of concerted elimination reactions (see reactions (11) and (14)), newly introduced in the present reaction mechanism, are also seen from Fig. 10(b). Further, the peroxy radical isomerization (for instance MCH3OO) to hydroperoxy methylcyclohexyl radical (MCHQ-T6) and the decomposition of peroxy hydroperoxy methylcyclohexyl radical (MCHQQJT6, MCHXQ2QJ) to form ketohydroperoxide (MCHQOT6, CHXCHO2Q) and $\mathrm{OH}$ also play an important role at this temperature.

At lower temperatures, $T \sim 770 \mathrm{~K}$, where the intermediate ignition behavior is manifest, the ignition delays are most impacted by the rate of cyclic ether (MCHYO24) formation from the hydroperoxyl methylcyclohexyl radical (MCHQ-T6) as seen from Fig. 10(c). In the low temperature ignition regime, this reaction ceases to be significant for the ignition delay predictions, as seen from the results of the sensitivity analysis performed at $T \sim 660 \mathrm{~K}$ 
presented in Fig. 10(d), The chain branching reactions, i.e. the decomposition of peroxy hydroperoxy methylcyclohexyl radical (for instance, MCHQQJ-T6) to form ketohydroperoxide (MCHQO-T6) and $\mathrm{OH}$, and the further decomposition of ketohydroperoxide to give $\mathrm{OH}$ radicals impact the ignition delays at these low temperatures.

The reaction flux analysis at $1250 \mathrm{~K}$ discussed above highlights the importance of thermal decomposition pathways of the methylcyclohexyl radicals at these high temperatures. Considering the integrated production and consumption rates after ignition at 20 atm at about $900 \mathrm{~K}$, that is, at the start of the NTC ignition regime occurs in Fig. 8(b) the methylcyclohexyl radicals dominantly react via the addition of oxygen molecule to form peroxy radicals, and the importance of thermal decomposition reactions diminishes. The peroxy radicals, for instance, $\mathrm{MCH} 4 \mathrm{OO}$, primarily react through (i) an internal H-atom abstraction involving a 6-membered ring transition state $(\sim 60 \%)$, such as in MCH4OO $\rightleftharpoons$ MCHQ-T6, (ii) concerted elimination pathway $(\sim 27 \%)$, and (iii) internal $\mathrm{H}$ atom abstraction involving a 5-membered ring transition state $(\sim 13 \%)$. For the $\gamma$-QOOH radical (MCHQ-T6), the main reaction pathways are the formation of cyclic ether and methylhexenone $(\sim 93 \%)$ with the loss of $\mathrm{OH}$, while the oxygen molecule addition pathway $\left(\mathrm{QOOH}+\mathrm{O}_{2}\right)$ is negligible $(\sim 3 \%)$. The cyclic ether produced from $\gamma$-QOOH radical decomposes into lumped methylhexenal species, following the detailed Pitz et al. 31. model.

The decomposition reactions of the $\gamma-\mathrm{QOOH}$ radicals (forming cyclic ether and methylhexenones, see Fig. 2(b) and the oxygen molecule addition pathway compete at moderate temperatures $\sim 720-830 \mathrm{~K}$ in Fig. 8(b) and twostage ignition prevails at these temperatures. At lower temperatures $(T<700 \mathrm{~K})$, the oxygen addition to $\mathrm{QOOH}$ leading to a branching pathway is increasingly favored to the detriment of cyclic ether formation, while the $\beta$ scission of $\gamma$-QOOH radical to form methylhexenenone remains important, a behavior also observed using the Pitz et al. 31] model.

\subsubsection{Methylcyclohexane $/ \mathrm{O}_{2} / \mathrm{Ar}$ ignition delays}

Ignition delay time measurements have been obtained at near-atmospheric pressures by Hong et al. 35] for mixtures of methylcyclohexane $/ \mathrm{O}_{2}$ in Argon, at $\phi=0.5$ and $\phi=1.0$. A comparison between the predicted ignition delay times and the experimental data is displayed in Figs. 11(a) and 11(b) and shows good agreement at high temperatures $(T>1400 \mathrm{~K})$.

In contrast, the CPM model predicts ignition delays that are longer these experimental data by a factor of $\sim 2$ (not shown here), highlighting the importance of the changes introduced to the CPM model discussed in section 2.3. While the correction introduced to the rate of vinyl radical addition to the internal double bonded carbon in propene (reaction (7) ) makes the ignition delays longer, the remaining reaction rate changes, which, as discussed in section 2.3. were found to be important at high temperatures, result in shorter ignition delays. In short, these changes include (a) the revised methylcylohexane isomerization pathway to form heptenes and (b) the updated rate constants for (i) the ring opening and closing of methylcyclohexyl radicals, (ii) H-abstraction from methylcyclohexane by different radicals, and (iii) the alkenyl decomposition reactions.

While the simulations compare well with the experimental data of Hong et al. 35], a comparison against the data from Orme et al. 30, and Vasu et al. 48, at atmospheric pressure in Figs. 11(c) and 11(d), shows some differences. The simulations underpredict the ignition delays measured by Orme et al. [30] at all conditions. However, considering the scatter in these experimental data, the simulation results still remain favorable.

\subsection{Time histories of species profiles}

Near atmospheric pressures. Hong et al. 35. measured $\mathrm{OH}$ and $\mathrm{H}_{2} \mathrm{O}$ profiles during methylcyclohexane $/ \mathrm{O}_{2} / \mathrm{Ar}$ oxidation at $\phi \sim 0.85$ and $P=2.2$ atm in a shock tube facility. The computed species profiles are compared with the experimentally measured profiles of Hong et al. in Fig. 12. The predictions show good agreement with the experimental peak values of $\mathrm{OH}$ and $\mathrm{H}_{2} \mathrm{O}$ time-histories at all temperatures. The predicted rise of $\mathrm{OH}$ and $\mathrm{H}_{2} \mathrm{O}$ profiles follow the experiments at these conditions, although being faster than the experiments.

A reaction flux analysis was carried out to understand the consumption routes of $\mathrm{OH}$ at the experimental conditions of Hong et al. 35 and $T=1435 \mathrm{~K}$. As the reaction progresses to the ignition point, the $\mathrm{OH}$ radicals are initially consumed mainly by the $\mathrm{H}$-abstraction by $\mathrm{OH}$ from methylcyclohexane, to produce different radicals of the fuel. Apart from the $\mathrm{H}$-abstraction reactions, the main decay pathway for the fuel at these conditions is the unimolecular decomposition into methyl and cyclohexyl radicals, given by

$$
\mathrm{MCH} \rightarrow \mathrm{CYCHEXRAD}+\mathrm{CH}_{3} .
$$

The methyl radicals generated by this pathway, as well as the decomposition of MCHR2 radicals into methyl radicals and cyclohexene (according to reaction 22,), contribute increasingly to the consumption of $\mathrm{OH}$ as the reaction proceeds, through $\mathrm{CH}_{3}+\mathrm{OH} \rightleftharpoons \mathrm{S}-\mathrm{CH}_{2}+\mathrm{H}_{2} \mathrm{O}$.

At later times, with the continued depletion of the fuel, smaller alkenes such as $\mathrm{C}_{2} \mathrm{H}_{4}$ are formed due to the decomposition of the branched and unbranched alkenyl radicals resulting from the ring opening of the methylcyclohexyl radicals. Increasingly larger amounts of $\mathrm{OH}$ radicals are used in the $\mathrm{H}$-abstraction reactions from ethylene, as well as from cyclohexene, $\mathrm{C}_{3} \mathrm{H}_{6}, \mathrm{C}_{2} \mathrm{H}_{6}$ (produced from the recombination of methyl radicals), and $\mathrm{C}_{4} \mathrm{H}_{6}$, although in smaller amounts than $\mathrm{C}_{2} \mathrm{H}_{4}$. This process continues until the depletion of the smaller alkenes and alkanes. The concentration of $\mathrm{OH}$ then increases rapidly denoting the 


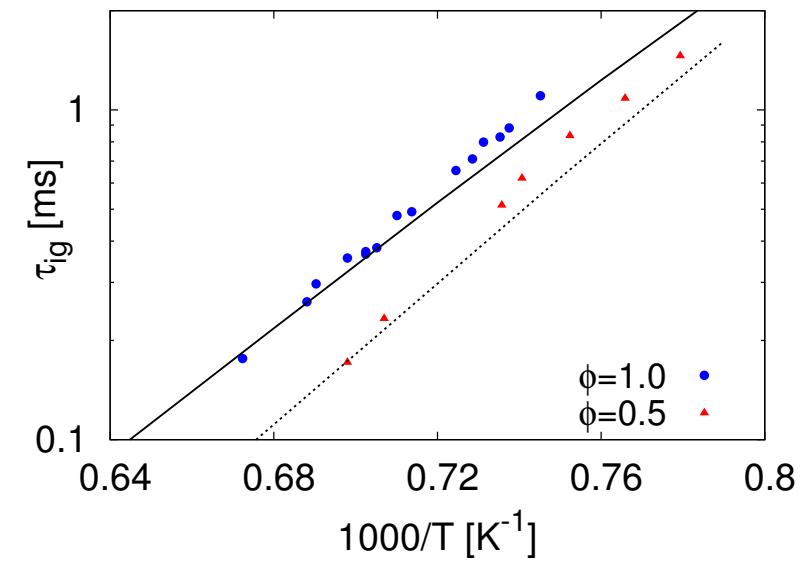

(a) $P=1.5$ atm; symbols - Hong et al. 35

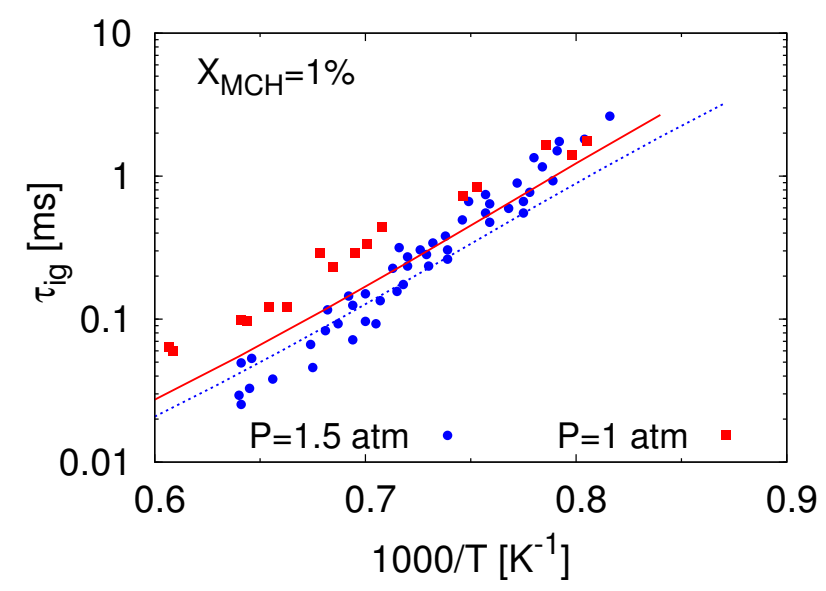

(c) $\phi=1.0$; symbols - Vasu et al. 48 (•), Orme et al. 30 (-)

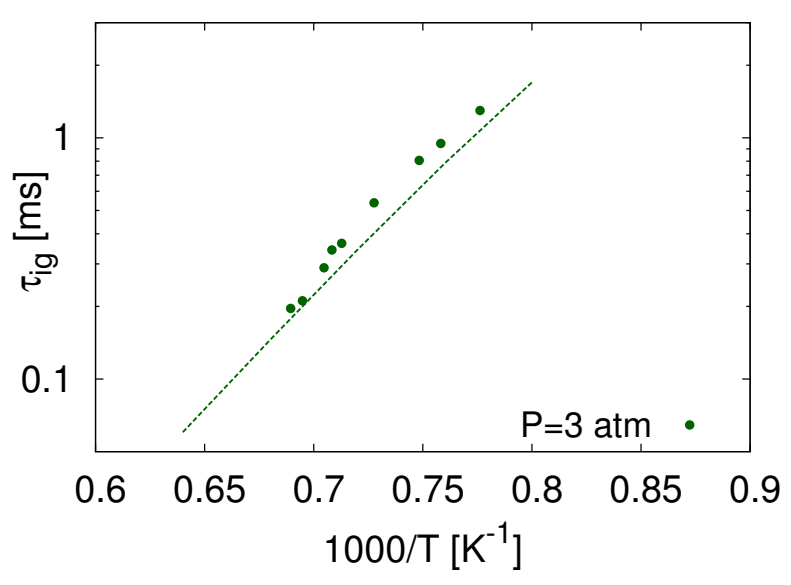

(b) $\phi=1.0$; symbols - Hong et al. 35.

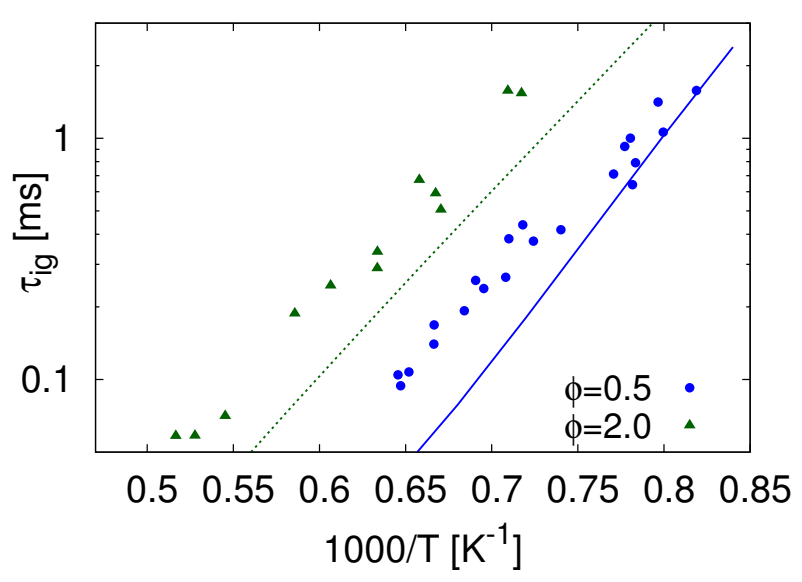

(d) $P=1$ atm; symbols - Orme et al. 30

Figure 11: Ignition delay times of methylcyclohexane $/ \mathrm{O}_{2} / \mathrm{Ar}$ mixtures; symbols - experimental data from Hong et al. 35, Vasu et al. 48, and Orme et al. [30; lines - simulations (using the present reaction scheme). 


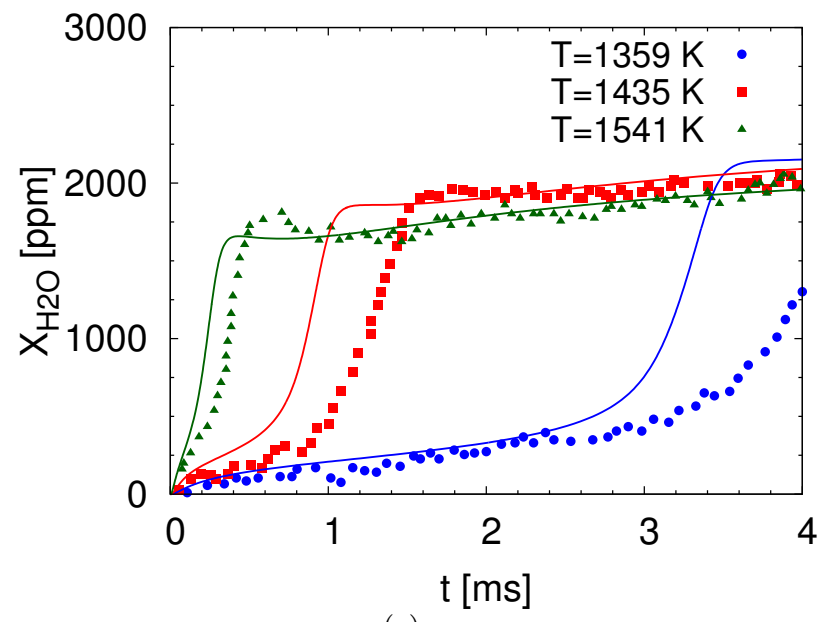

(a)

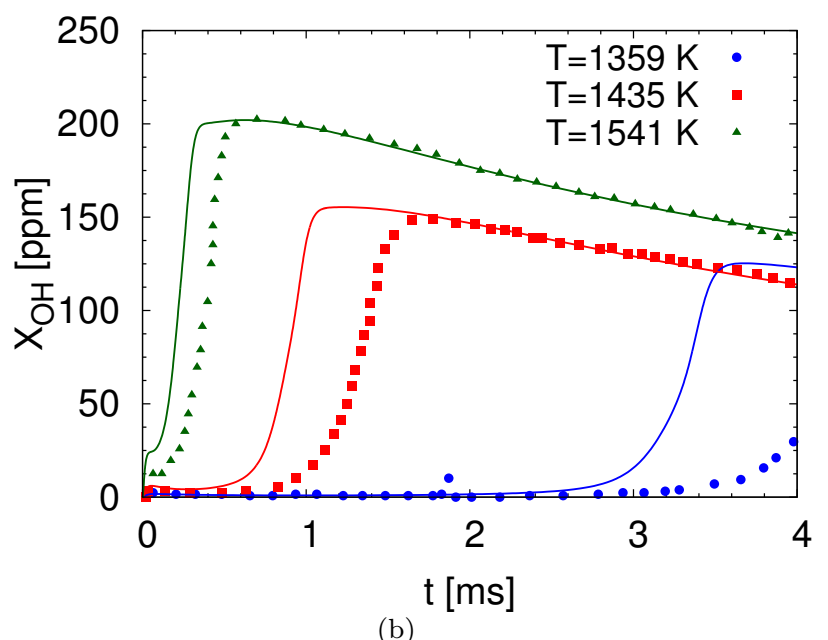

(b)

Figure 12: Species time-histories during methylcyclohexane $/ \mathrm{O}_{2} / \mathrm{Ar}$ oxidation. Conditions: $(1) T=1359 \mathrm{~K}, P=2.2 \mathrm{~atm}$, $380 \mathrm{ppm} \mathrm{MCH} / 4200 \mathrm{ppm} \mathrm{O}_{2} / \mathrm{Ar}, \phi=0.95$, (2) $T=1435 \mathrm{~K}, P=2.2 \mathrm{~atm}, 340 \mathrm{ppm} \mathrm{MCH} / 4200 \mathrm{ppm} \mathrm{O} / \mathrm{Ar}, \phi=0.85,(3) T=1541 \mathrm{~K}, P=$ $2.1 \mathrm{~atm}, 320 \mathrm{ppm} \mathrm{MCH} / 4200 \mathrm{ppm} \mathrm{O} \mathrm{O}_{2} / \mathrm{Ar}, \phi=0.80$; symbols - experimental data from Hong et al. [35; lines - $\mathrm{OH}_{\text {and }} \mathrm{H}_{2} \mathrm{O}$ profiles computed using the present reaction scheme.

point of ignition in Fig. 12. The importance of net rates of methylcyclohexyl ring opening reactions is particularly evident from this discussion. The revised rate constants adopted in this work for these reactions as well as other reactions identified as important at high temperatures in section 2.3 impact the predicted $\mathrm{OH}$ profiles.

High pressures. Vasu et al. 49 measured $\mathrm{OH}$ profiles during oxidation of methylcyclohexane, with initial $X_{\mathrm{MCH}}=$ $1000 \mathrm{ppm}, X_{\mathrm{O}_{2}}=0.021$, balance Ar, at an equivalence ratio of $\phi=0.5$ and a pressure of $P=15 \mathrm{~atm}$. It is interesting to note that some of the existing kinetic schemes for methylcyclohexane show varied $\mathrm{OH}$ concentration predictions compared to these experimental data, with jetSurF [32] showing the best agreement (see Fig. S4 in Supporting materials). The $\mathrm{OH}$ profiles predicted using the present reaction scheme are compared with the experimentally measured profiles in Figs. 13(a) and 13(b). The agreement of the peak $\mathrm{OH}$ value, and the time of $\mathrm{OH}$ rise has improved significantly compared to the CPM model predictions shown in Fig. 3(b).

The predicted $\mathrm{OH}$ profiles are significantly influenced by the changes associated with reactions of biradicals introduced into the model as described in section 2.3. With the biradical pathways as described in the CPM model, the recombination of two ethylene molecules to give butyl biradicals (reverse of reaction (5)), and the recombination of an ethylene and propene to give pentyl biradicals (reverse of reaction (6)), consume nearly $90 \%$ ethylene and $74 \%$ propene at these conditions. Due to these competing pathways, the rate of $\mathrm{H}$-abstraction by $\mathrm{OH}$ radicals from these small alkenes is reduced. As a consequence, with little formation of the highly reactive vinyl radicals (via $\mathrm{H}$-abstraction from ethylene), the reactivity of the system is very low, resulting in a delayed rise in $\mathrm{OH}$ pro- files. The revised treatment of the ring opening reaction of methylcyclohexane to give heptene as product (bypassing the biradicals, see section 2.3), incorporated in the present work, helps achieve improved $\mathrm{OH}$ profiles when compared to the experiments. In addition, those reaction rate changes identified as important at high temperatures in section 2.3. also impact the time instant of $\mathrm{OH}$ rise at these conditions.

The simulated $\mathrm{OH}$ profiles follow the experimental data in Figs. 13(a) and 13(b), with the point of $\mathrm{OH}$ rise and the peak $\mathrm{OH}$ concentrations predicted within $20 \%$ of the measurements at different temperatures. Vasu et al. also measured $\mathrm{OH}$ profiles at lower initial fuel concentration, $X_{\mathrm{MCH}}=750 \mathrm{ppm}$, and the same equivalence ratio and pressure conditions as above. In Fig. 13(c), a comparison between the simulations and experimental data is presented.

The peak $\mathrm{OH}$ concentrations predicted by the simulations remain within $10 \%$ of the experimental data at the higher temperatures, $T \gtrsim 1260 \mathrm{~K}$, considered in Fig. 13(c), similar to the previous case, while the time instant of $\mathrm{OH}$ rise is delayed in the simulations by $\sim 40 \%$ at $1266 \mathrm{~K}$. Ignition delays were also reported by Vasu et al. 49] at the same conditions at which the $\mathrm{OH}$ profiles were obtained. These data are compared to the ignition delay times computed using the present chemical model in Fig. 13(d) The longer ignition delay predictions compared to the experimental data for $X_{\mathrm{MCH}}=750 \mathrm{ppm}$ mixtures are consistent with the delayed rise in the $\mathrm{OH}$ time history predicted by the simulations at those conditions.

\subsection{Species Profiles in a Plug Flow Reactor}

Rich oxidation. High temperature oxidation of methylcyclohexane/air mixtures was studied by Zeppieri et al. 22] 


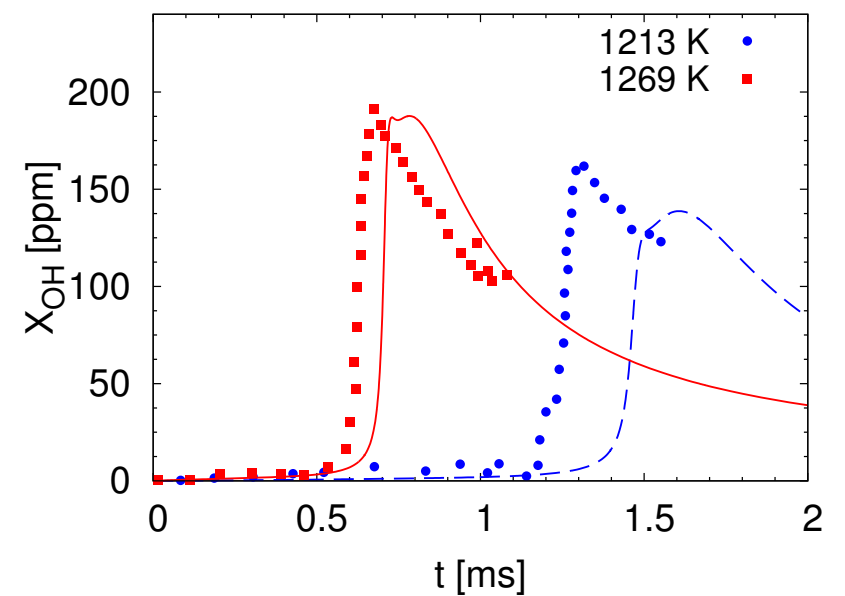

(a) OH time history; Initial $X_{\mathrm{MCH}}=1000 \mathrm{ppm}$

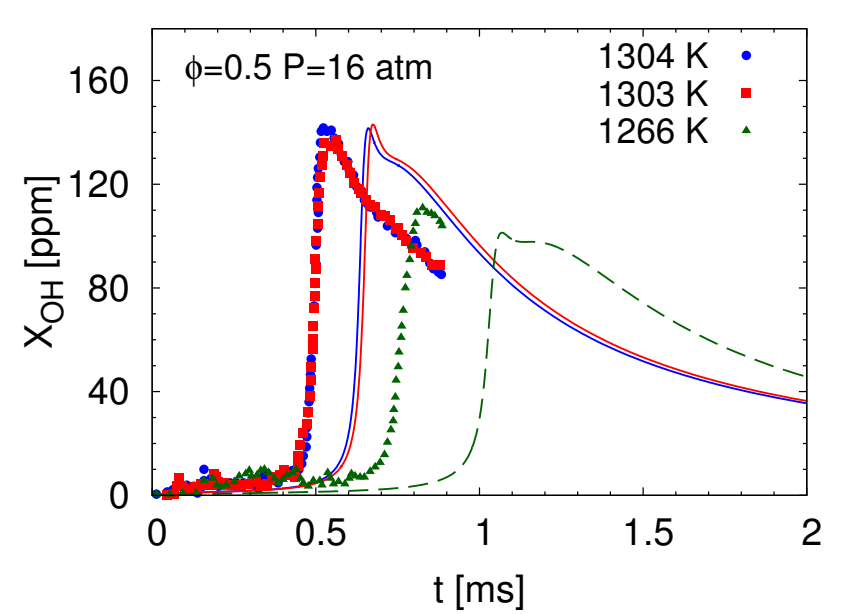

(c) OH time history; Initial $X_{\mathrm{MCH}}=750 \mathrm{ppm}$

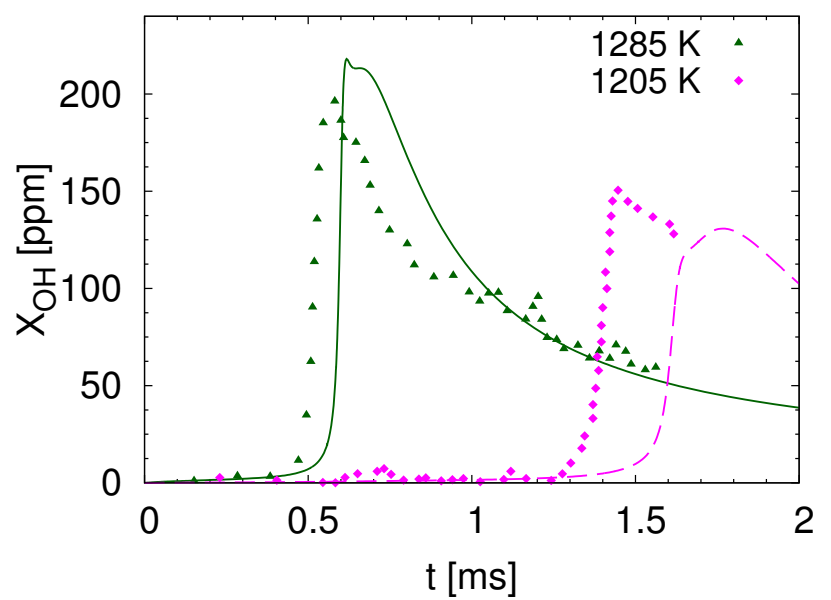

(b) $\mathrm{OH}$ time history; Initial $X_{\mathrm{MCH}}=1000 \mathrm{ppm}$

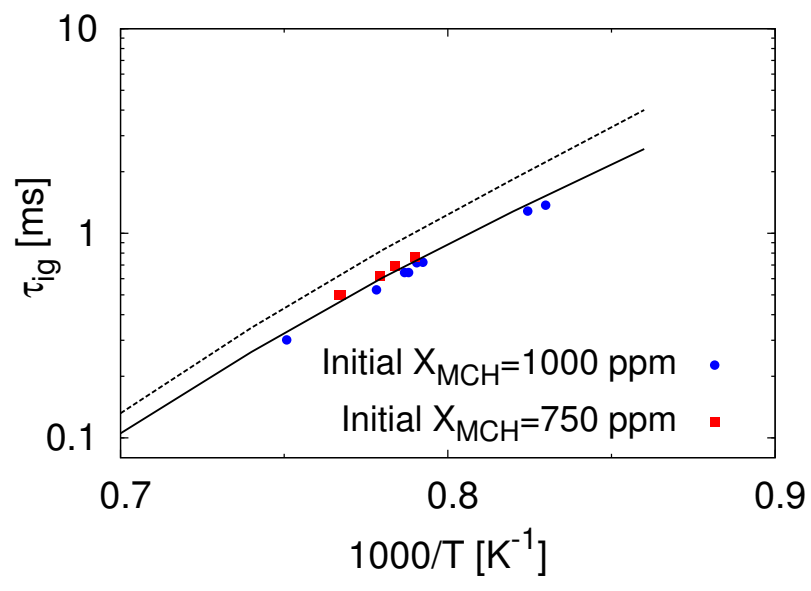

(d) Ignition delays corresponding to Figs. $13(\mathrm{a})$ 13(c)

Figure 13: Methylcyclohexane $/ \mathrm{O}_{2} /$ Ar oxidation at $\phi=0.5$ and $P=16 \mathrm{~atm}$; (a) and (b) - OH profiles at initial fuel concentration $\left(X_{\mathrm{MCH}}\right)=1000 \mathrm{ppm}(\mathrm{c})-\mathrm{OH}$ profiles at initial $X_{\mathrm{MCH}}=750 \mathrm{ppm}$, (d) ignition delay times corresponding to the experimental conditions of (a), (b) (•), and (c) (•); symbols - experimental data from Vasu et al. [49]; lines - results computed using the present reaction scheme. 
in the Princeton Turbulent Flow Reactor. They measured concentrations of methylcyclohexane, as well as typical major and minor species formed during its oxidation. The experimental data was obtained at $P=1 \mathrm{~atm}, T=$ $1160 \mathrm{~K}$, initial MCH concentration of $1815 \mathrm{ppm}$, and fuel/air mixture ratio of $\phi=1.3$.

A comparison between the species concentration time evolution predicted using the present kinetic scheme and the experimental data is presented in Fig. 14. The experimental data have been shifted by $5 \mathrm{~ms}$ relative to the simulations to account for the experimental uncertainties in the zero-time specification [71. The zero-time shift is chosen here to give the best agreement between the experimental and predicted fuel consumption profiles.

In Fig. 14(a), the fuel decay follows the experimental measurements, while the rise in temperature is slightly shifted towards larger residence times. This is also consistent with the shift seen in $\mathrm{CO}_{2}$ profile in Fig. 14(b) and therefore, an improvement in temperature profile is expected to result in better $\mathrm{CO}_{2}$ profiles as well. The simulated profiles of CO in Fig. 14(b), and smaller alkane, alkene, and dienes in Figs. 14(c) 14(d) and 14(e) follow the experiments closely. The amounts of cyclopentadiene and benzene predicted from the simulations are comparable to the experiments in Fig. 14(f). The overall agreement between the model predictions and the experimental measurements is favorable. The results obtained using the present kinetic scheme show improved predictions of the flow reactor data compared to the reference Pitz et al. 31 . reaction mechanism, and this is discussed in better detail as part of the Supporting materials (Fig. S3).

A reaction flux analysis revealing the important consumption pathways of the fuel and the different intermediates at the experimental conditions of Zeppieri et al. [29] is presented in Fig. 15. The fuel, methylcyclohexane (MCH), is consumed mainly by $\mathrm{H}$-abstraction reactions producing different methylcyclohexyl radicals. The fuel also undergoes a unimolecular decomposition into cyclohexyl and methyl radicals. The $\mathrm{H}$-abstraction reactions from the fuel by methyl radical contribute significantly to the methane observed in Fig. 14(c). The recombination of methyl radicals produces the ethane observed in Fig. 14(c). The ring opening of methylcyclohexyl radicals, followed by the decomposition of the branched alkenyl radicals, contributes to the alkenes: ethylene, propene, isoprene $\left(i-\mathrm{C}_{5} \mathrm{H}_{8}\right)$, butadiene, and cyclopentadiene in Figs. 14(d) 14(e), and 14(f) as can be inferred from the reaction flux chart in Fig. 15. The figure also shows the pathways for the formation of aromatic species, benzene $\left(\mathrm{A}_{1}\right)$ and toluene $\left(\mathrm{A}_{1} \mathrm{CH}_{3}\right)$, from methylcyclohexane oxidation, which were discussed previously in section 2.3 .

Zeppieri et al. 29] also studied the pyrolysis of methylcyclohexane at atmospheric pressure and an initial temperature of $T=1155 \mathrm{~K}$. The simulation results are compared for this case against the experimental measurements in the Supporting materials (Fig. S5).

\subsection{Laminar flame speeds}

Several experimental studies have measured laminar flame speeds of methylcyclohexane/air mixtures using different measurement techniques. At atmospheric pressure and an unburnt temperature of $T_{u}=353 \mathrm{~K}$, Ji et al. 38 determined flame speeds in a counterflow configuration. $\mathrm{Wu}$ et al. 39] measured propagation speeds of spherically expanding methylcyclohexane/air flames at atmospheric and elevated pressures with $T_{u}=353 \mathrm{~K}$. Similar techniques were used by Singh et al. 37 to measure flame speeds at $P=1 \mathrm{~atm}$ and $T_{u}=400 \mathrm{~K}$. Also, Kumar and Sung [36] used a counterflow twin-flame technique to determine flame speeds of methylcyclohexane/air mixtures at the same conditions.

The flame speeds computed using the present reaction scheme are compared with these experimental data at varying pre-heat temperatures and pressures in Figs. 16(a) and 16(b) respectively. Considering flame speeds at atmospheric pressures shown in Fig. 16(a) at $T_{u}=400 \mathrm{~K}$, the model predictions are within the variability of the available experimental measurements. At $T_{u}=353 \mathrm{~K}$, the computed flame speeds agree closely with at least one set of measurements for all mixture ratios, with a slight overprediction at near stoichiometric conditions. Flame speed predictions are improved at higher pressures, as comparisons with the Wu et al. 39 data demonstrate (Fig. 16(b).

Note that the detailed Pitz et al. mechanism [31 has not been validated for premixed flames configurations. Nevertheless, the flame speeds simulated using the kinetic scheme proposed here show satisfactory agreement with the experimental data, pointing towards an overall adequate description of $\mathrm{H}$ and $\mathrm{CH}_{3}$ radicals, known to be important for laminar flame speed predictions.

\subsection{Species profiles in premixed flames}

Wang et al. [33, 69] investigated lean, stoichiometric, and rich premixed methylcyclohexane flames using synchrotron vacuum ultraviolet photoionization mass spectrometry (SVUV-PIMS) at a low pressure of 30 torr. They measured concentrations of several species in these flames. The uncertainties in the mole fractions are reported as about $\pm 10 \%$ for the major species, about $\pm 25 \%$ for intermediate species with known photoionization cross sections (PIC), and a factor of 2 for those with estimated PICs. Their detailed measurements enable a careful evaluation of the reaction mechanism with regard to the individual reaction pathways that play an important role at these experimental conditions as well as their kinetic rate constants. A comparison against their experimental data for the rich flame $(\phi=1.75)$ is shown in Figs. 17,19 The model is also compared to their stoichiometric and lean experimental data in the Supplementary materials (Figs. S6$\mathrm{S} 11)$. The temperature profile is prescribed from the experiments [33, 69] in the present simulations. These comparisons should, however, be taken with caution, since the experimental data have been obtained at very low pressure $(P=30$ torr, i.e. 40 mbar $)$, which may fall outside 


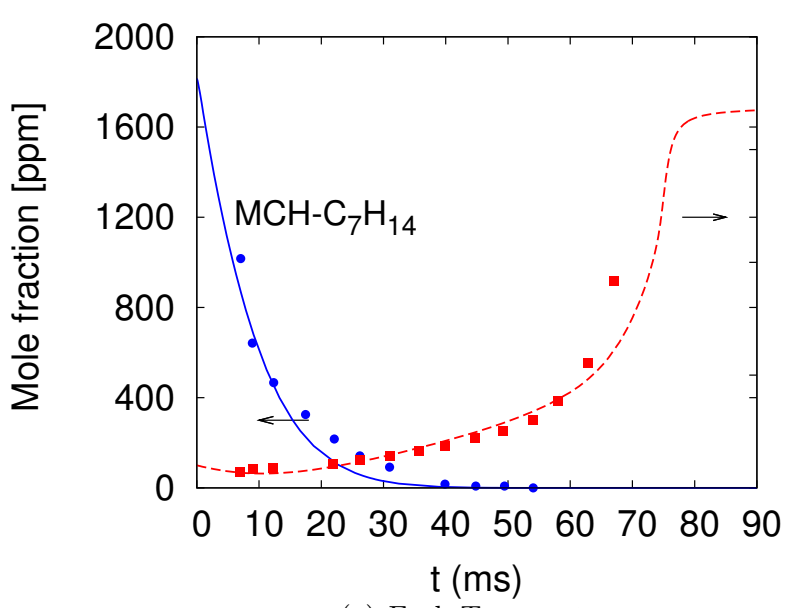

(a) Fuel, Temperature

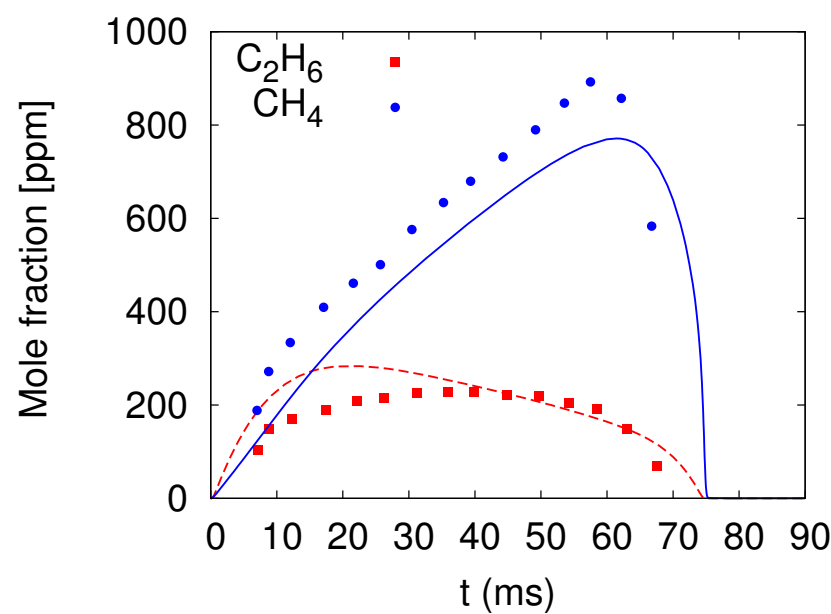

(c) Small alkanes

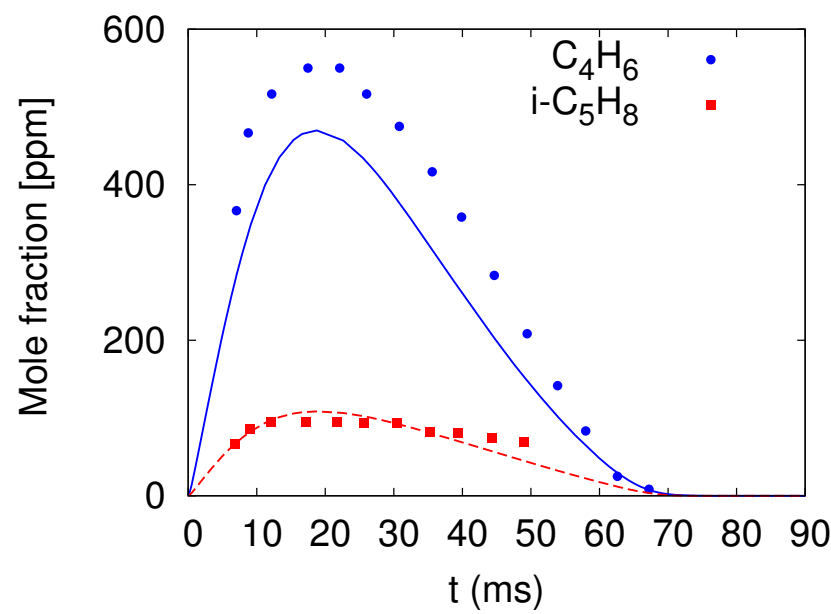

(e) Dienes

1350

1300

1250

1200

1150

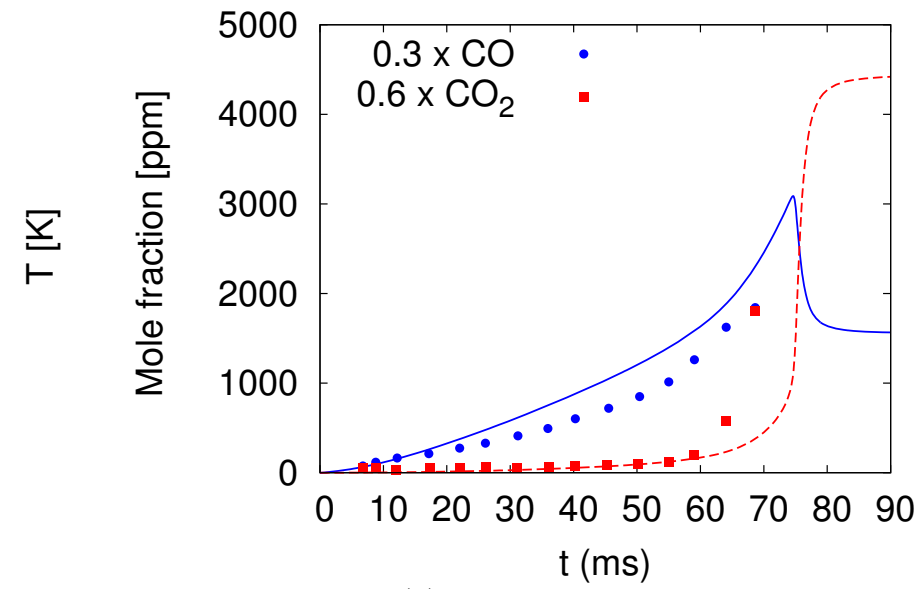

(b) Carbon oxides

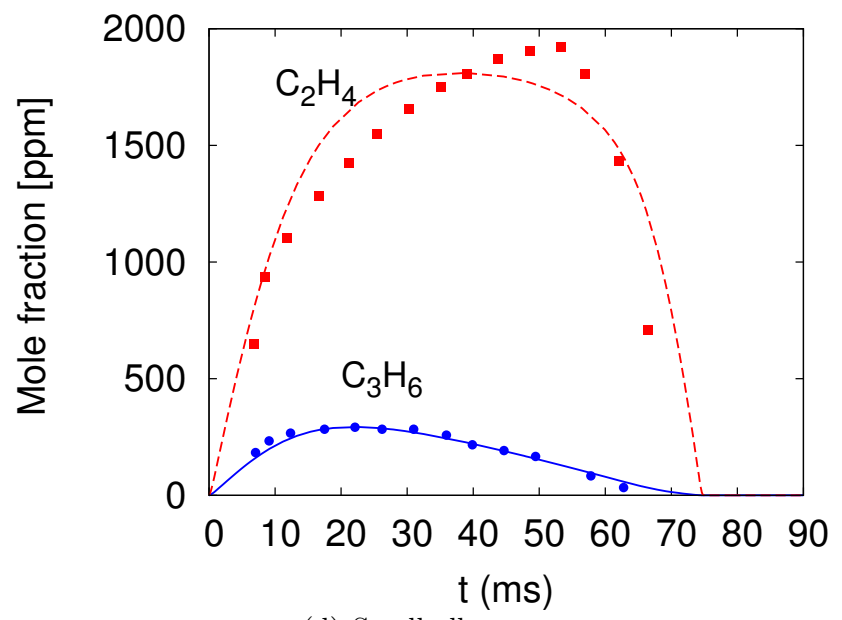

(d) Small alkenes

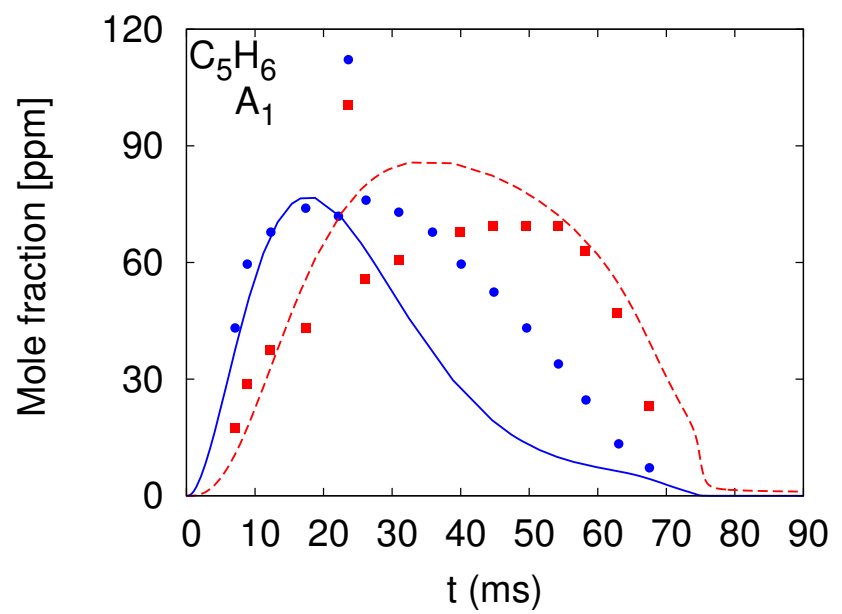

(f) Minor species

Figure 14: Time evolution of major species during methylcyclohexane/air oxidation in a plug flow reactor at $\mathrm{P}=1 \mathrm{~atm}, T=1160 \mathrm{~K}$, and $\phi=1.3$, with initial $\mathrm{X}_{\mathrm{MCH}}=1815 \mathrm{ppm}$; symbols - experimental data from Zeppieri et al. [29], shifted by 5 ms; lines - species profiles computed using the present reaction scheme. 


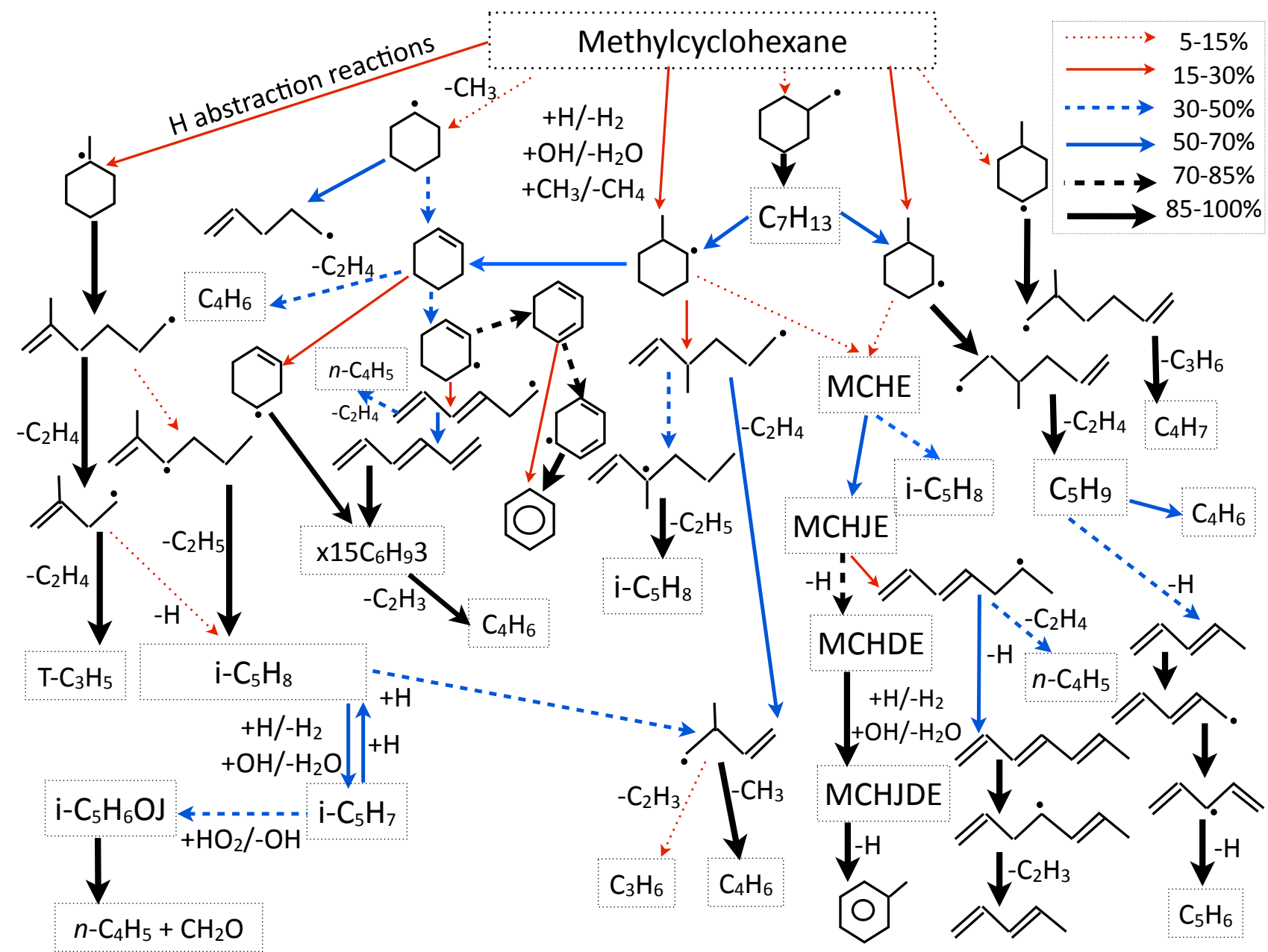

Figure 15: Reaction flux analysis performed at the experimental conditions of Zeppieri et al. 29] in Fig. 14, at a time when $\sim 36 \%$ of the initial fuel is consumed. This chart reveals the important consumption pathways of the fuel and different intermediates at this condition.

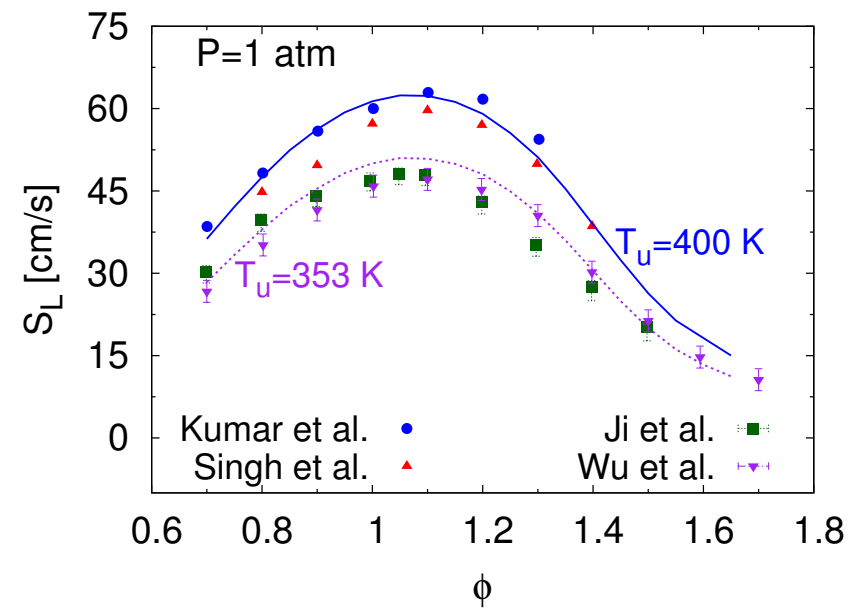

(a) Varying pre-heat temperatures: $T_{u}=353,400 \mathrm{~K}$

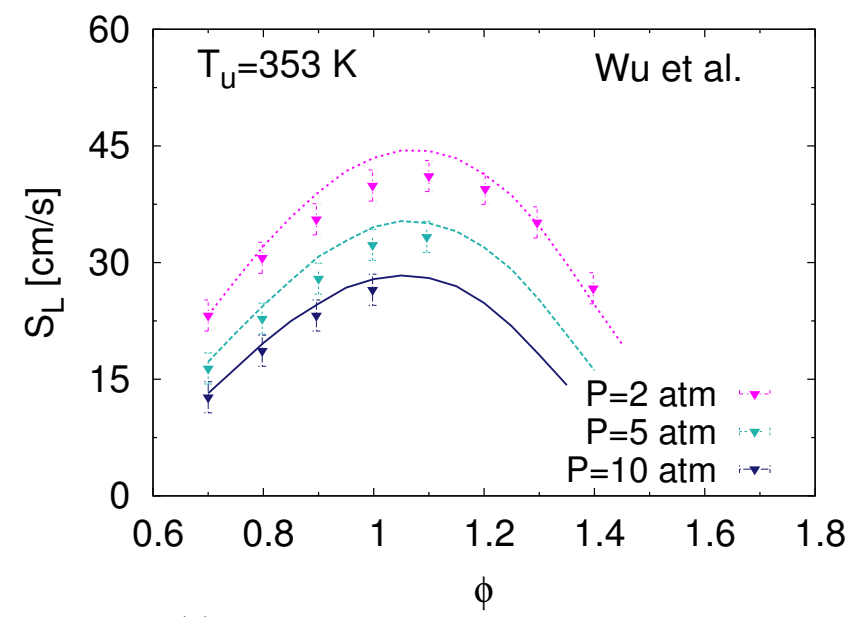

(b) Varying pressures: $P=2,5,10 \mathrm{~atm}$

Figure 16: Laminar flame propagation speeds of methylcyclohexane/air mixtures; symbols - experimental data from Kumar and Sung [36], Singh et al. 37, Ji et al. 38, Wu et al. 39]; lines - flame speeds computed using the present reaction scheme. 

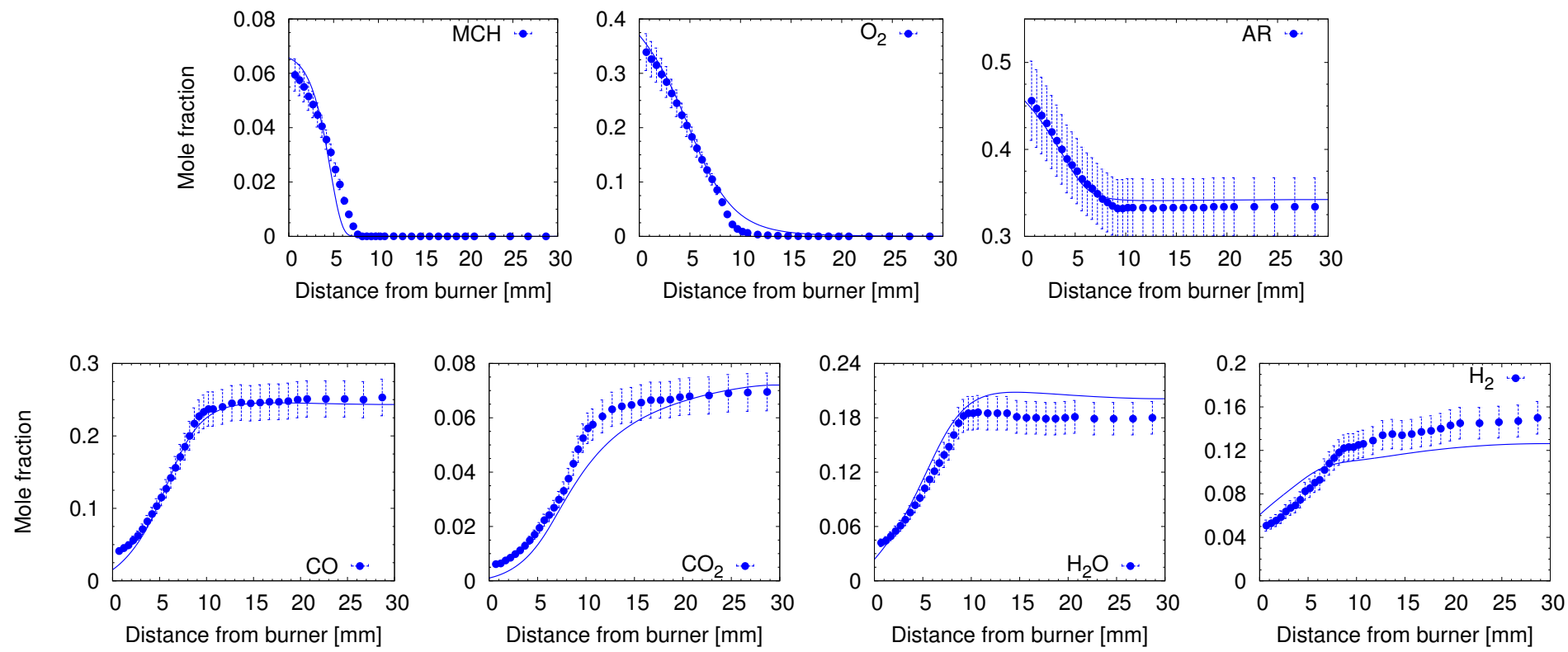

Figure 17: Mole fraction profiles of major species in the premixed flame with equivalence ratio $\phi=1.75$; symbols: experimental data from Wang et al. [33, 69]; lines - mole fractions computed using the present reaction scheme. The temperature profile is prescribed from the experiments 33,69 .

of the range of validity of the present mechanism due to reactions whose rate constants are not prescribed for those low pressures.

\section{Fuel decay pathways}

The major species profiles are shown in Fig. 17. The simulations show good agreement with the experimental data for the fuel, oxidizer, and inert gas, as well as the major products $\mathrm{CO}, \mathrm{CO}_{2}, \mathrm{H}_{2}$, and $\mathrm{H}_{2} \mathrm{O}$. The fuel, methylcyclohexane, is predominantly consumed via $\mathrm{H}$ abstraction reactions by $\mathrm{H}(\sim 50 \%), \mathrm{OH}(\sim 23 \%)$, and $\mathrm{O}(\sim 8 \%)$ radicals. About $15 \%$ of the fuel decomposes to form methyl and cyclohexyl radical, while a small percentage of the fuel $(\sim 4 \%)$ forms heptenes via ring opening followed by isomerization. For the stoichiometric and lean flames, the fuel decay (Fig. S6 and S9 in the Supporting materials) proceed entirely via $\mathrm{H}$-abstraction routes, primarily by $\mathrm{H}$ and $\mathrm{OH}$ radicals.

\section{$\mathrm{C}_{1}-\mathrm{C}_{5}$ species}

The simulated $\mathrm{C}_{1}-\mathrm{C}_{5}$ intermediates profiles are compared with the experiments in Fig. 18. These intermediates get consumed within $15 \mathrm{~mm}$ from the burner, with the complete consumption of oxidizer. As noted by Wang et al. [33, the measured data at distances shorter than $2 \mathrm{~mm}$ from the burner surface might not represent the true species mole fractions, mainly due to the perturbation of the sampling nozzle. This may contribute to the large discrepancy observed between the experiments and the simulation close to the burner surface.

The computed profiles of $\mathrm{C}_{3} \mathrm{H}_{6}, \mathrm{CH}_{2} \mathrm{O}, \mathrm{C}_{4} \mathrm{H}_{6}$ (butadiene), $\mathrm{C}_{5} \mathrm{H}_{6}$ (cyclopentadiene), and $\mathrm{C}_{5} \mathrm{H}_{8}$ (includes $1,3-$ pentadiene and isoprene) agree well with the experiments. The simulated profiles of methyl, acetylene, and propargyl $\left(\mathrm{C}_{3} \mathrm{H}_{3}\right)$ follow the experiments up to a distance of $8 \mathrm{~mm}$ from the burner surface, but display a slower decay at larger distances. This trend is also seen in the simulated results of Wang et al. 33.

For this flame, in addition to the contribution from the small hydrocarbon chemistry, the beta-scission of the branched heptenyl $\left(\mathrm{C}_{7} \mathrm{H}_{13}\right)$ radicals formed from the ring opening of the methylcyclohexyl radicals contributes about $25 \%$ and $10 \%$ to the formation of ethylene and propene respectively. The formation pathways of butadiene, cyclopentadiene, and $\mathrm{C}_{5} \mathrm{H}_{8}$ also directly involve intermediates found in the methylcyclohexane sub-mechanism.

About $35 \%$ of butadiene formation comes from $\mathrm{C}_{5} \mathrm{H}_{9}$ with the loss of a methyl radical, where $\mathrm{C}_{5} \mathrm{H}_{9}$ is entirely produced from the beta scission of the branched heptenyl radical $\mathrm{kC}_{7} \mathrm{H}_{13} \mathrm{~g}$ (4-methyl-2-hexen-6-yl). Further, the decomposition of $\mathrm{cC}_{5} \mathrm{H}_{9}$ a and hexenyl radicals account each for $\sim 15 \%$ to the formation of butadiene. About $17 \%$ of butadiene is formed from the decomposition of linear hexadienyl radical, and $\sim 15 \%$ comes from the unimolecular decomposition of cyclohexene (which is mainly formed from the decomposition of MCHR2 radicals).

All of the 1,3-pentadiene at the simulated condition comes from $\mathrm{C}_{5} \mathrm{H}_{9}$ radical with the loss of a $\mathrm{H}$ atom. Upon $\mathrm{H}$ abstraction on 1,3-pentadiene by $\mathrm{H}$ atom, the $\mathrm{C}_{5} \mathrm{H}_{7}$ radical is formed, which entirely converts to cyclopentadiene with the loss of a $\mathrm{H}$ atom. This pathway accounts for $\sim 95 \%$ of the formation of $\mathrm{C}_{5} \mathrm{H}_{6}$ at these conditions. About $15 \%$ of isoprene comes from the unimolecular decomposition of methylcyclohexene, while the rest comes from the 

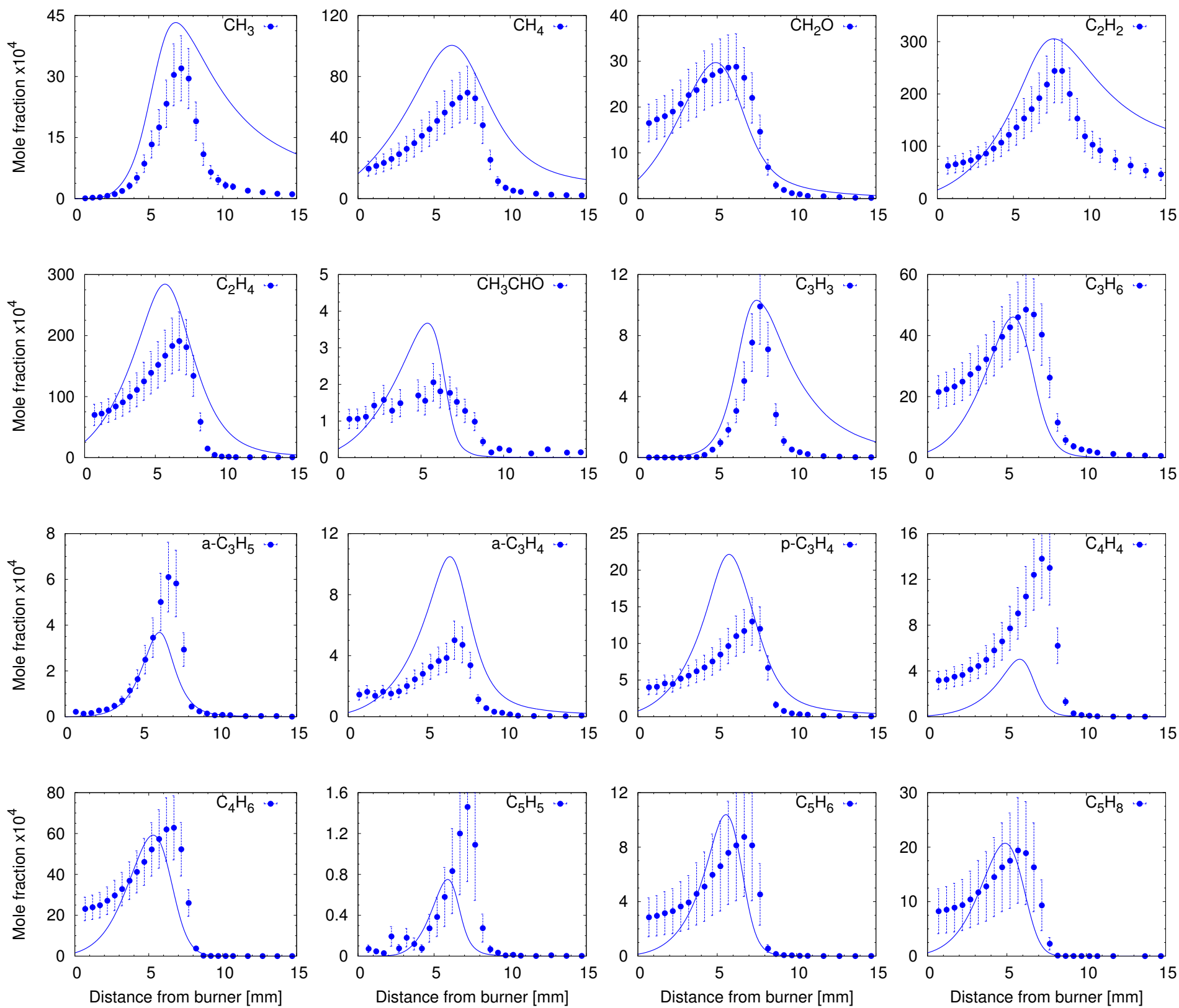

Figure 18: Mole fraction profiles of $\mathrm{C}_{1}-\mathrm{C}_{5}$ intermediates in the premixed flame with equivalence ratio $\phi=1.75$; symbols: experimental data from Wang et al. 33] 69]; lines - mole fractions computed using the present reaction scheme. The temperature profile is prescribed from the experiments 33,69 . The $\mathrm{C}_{5} \mathrm{H}_{8}$ species here includes both 1,3-pentadiene and isoprene. 

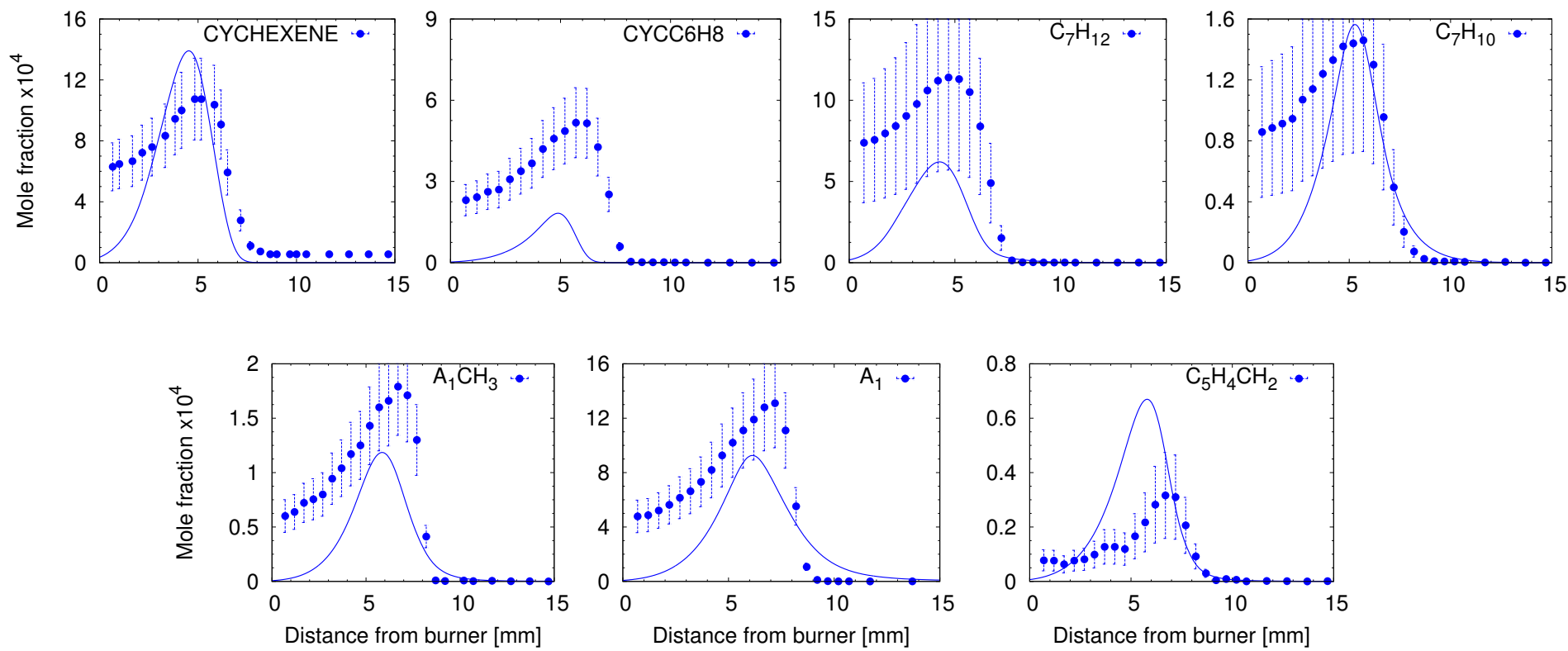

Figure 19: Mole fraction profiles of $\mathrm{C}_{6}$ and $\mathrm{C}_{7}$ intermediates in the premixed flame with equivalence ratio $\phi=1.75$; symbols: experimental data from Wang et al. [33, 69; lines - mole fractions computed using the present reaction scheme. The temperature profile is prescribed from the experiments [33, 69]. The $\mathrm{C}_{7} \mathrm{H}_{12}$ species here includes the methylcyclohexene isomers, CHXDCH2, linear 1,3- and 2,4-heptadienes; the $\mathrm{C}_{7} \mathrm{H}_{10}$ species includes methylcyclohexadiene and 1,3,5-heptatriene.

beta-scission of the branched heptenyl radicals (formed from the ring opening of the various methylcyclohexyl radicals).

Some discrepancies are seen in the $\mathrm{A}-\mathrm{C}_{3} \mathrm{H}_{5}$ (allyl), $\mathrm{A}-\mathrm{C}_{3} \mathrm{H}_{4}$ (allene), and $\mathrm{P}_{-} \mathrm{C}_{3} \mathrm{H}_{4}$ (propyne) profiles in Fig. 18, where the maximum predicted concentrations differ by up to a factor of two from the experiments. At stoichiometric and lean flame conditions, the simulated profiles of allene and propyne show a better agreement with the experimental data (see Figs. S7 and S10), while the allyl concentration is similarly underpredicted.

A reaction flux analysis reveals that at rich flame conditions, about $50 \%$ of the allene is formed from allyl radicals by the loss of a $\mathrm{H}$ atom, whereas this contribution decreases to $\sim 10 \%$ for the stoichiometric flame and becomes insignificant for the lean flame. This route also accounts for about half of the allyl radical consumption at the rich conditions. The addition of $\mathrm{H}$ atom to allyl to form propene is the other dominant pathway consuming allyl at these conditions. This is also the major allyl radical consumption pathway at stoichiometric and lean flame conditions. Considering the importance of these pathways, it could be surmised that improvements to allyl and allene profiles would require a more accurate reaction rate for $\mathrm{A}-\mathrm{C}_{3} \mathrm{H}_{5} \rightleftharpoons \mathrm{A}-\mathrm{C}_{3} \mathrm{H}_{4}+\mathrm{H}$ and $\mathrm{A}-\mathrm{C}_{3} \mathrm{H}_{5}+\mathrm{H} \rightleftharpoons \mathrm{C}_{3} \mathrm{H}_{6}$, relevant to the experimental conditions considered here. Subsequently, this could also improve propyne concentration profile, since about $35 \%$ of propyne is formed from allene at the rich flame conditions.

\section{Benzene and Toluene}

The computed $\mathrm{C}_{6}$ and $\mathrm{C}_{7}$ intermediates profiles are compared with the experiments in Fig. 19. Cyclohexene is mainly produced $(\sim 90 \%)$ from the methylcyclohexyl radical, MCHR2, with the loss of a methyl group. By $\mathrm{H}$ atom abstraction from cyclohexene, and further $\mathrm{H}$ atom elimination from the resulting resonantly stabilized cyclohexenyl radical, 1,3-cyclohexadiene $\left(\mathrm{CYCC}_{6} \mathrm{H}_{8}\right.$ in Fig. 19$)$ is formed, which by a similar sequence of pathways, leads to benzene. Likewise, methylcyclohexene (included in $\mathrm{C}_{7} \mathrm{H}_{12}$ in Fig. 19), which comes from the methylcyclohexyl radicals with the loss of a $\mathrm{H}$ atom, produces methylcyclohexadiene by a successive dehydrogenation pathway, which in turn leads to the formation of toluene.

The different pathways forming benzene in the rich flame considered here are shown in Fig. 20(a), The dehydrogenation pathway described above accounts for $\sim 45 \%$ of the benzene formed in the flame. The rest of the benzene comes from the aromatic chemistry well described in the base+aromatics mechanism [1, 4] on top of which the methylcyclohexane chemistry has been built. The $\mathrm{H}$ atom-assisted isomerization of fulvene contributes $\sim 23 \%$, propargyl radical recombination contributes $13 \%$, and the substitution of the methyl group in toluene by a $\mathrm{H}$ atom contributes $\sim 10 \%$ to formation of benzene. Fulvene is mainly produced from methyl addition to cyclopentadienyl radical $(\sim 49 \%)$, propargyl radical recombination $(\sim$ $40 \%)$, and CO elimination from cresoxy radical $(\sim 11 \%)$.

Note that one of the six isomers of methylcyclohexenyl (MCHJE) and methylcyclohexadienyl (MCHJDE) radicals lead to the formation of 1,3-cyclohexadiene and benzene, 
respectively, through the loss of a methyl group. The importance of these pathways have been investigated by assuming equal distribution of all isomers of MCHJE and MCHJDE radicals. In the presence of these pathways, the peak value of $\mathrm{A}_{1}$ increases by $\sim 3 \%$ and that of $\mathrm{A}_{1} \mathrm{CH}_{3}$ decreases by $\sim 10 \%$ from that shown in Fig. 19 . In the absence of information about the distribution of the individual MCHJE and MCHJDE isomers, these pathways have not been included in the proposed mechanism.

The pathways for the formation of toluene are simpler than benzene, and these are shown in Fig. 20(b). About $54 \%$ of the toluene comes from the dehydrogenation pathway starting from methylcyclohexene that was described above. The remaining toluene largely comes from methyl recombination with phenyl radicals, which are originally produced from benzene by $\mathrm{H}$ abstraction reactions.

The above discussion emphasizes that, in addition to the benzene and toluene formed from intermediates in the methylcyclohexane sub-mechanism, the existence of a well validated aromatic chemistry is crucial to predict these aromatic species profiles in accordance with the experiments. The predicted amounts of aromatic species compare well with the experimental data for the rich flame, as well as for the stoichiometric and lean flames (see Figs. S8 and S11). In all, it could be concluded with confidence that the detailed species concentrations observed in the burner stabilized flame set-up are well represented by the present kinetic scheme.

\section{Conclusions}

With the objective of a kinetic model for jet fuel and other transportation fuel surrogates, a reaction mechanism has been developed to describe the oxidation of methylcyclohexane as a representative naphthene molecule. This has been accomplished by starting with a chemical mechanism proposed earlier for smaller hydrocarbons along with a few substituted aromatics and $n$-dodecane [1, 4, 23] as the base model, and extending this model to include the reaction pathways of methylcyclohexane oxidation.

Starting with the detailed mechanism for methylcyclohexane proposed by Pitz et al. 31, a skeletal level mechanism for methylcyclohexane oxidation was obtained using reaction mechanism reduction techniques, which was then incorporated into the previous scheme. Sensitivity analysis and reaction flux analysis was used to identify fuel-dependent important reactions at different conditions. These reactions were then examined and rate changes supported by recent rate recommendations from literature were introduced, irrespective of whether these led to improvements or deterioration of the agreement with experimental data. Furthermore, an additional concerted elimination pathway important for ignition delay predictions at moderate to low temperatures was introduced to this combined model.

The resulting revised mechanism was comprehensively validated for methylcyclohexane oxidation against a large number of experimental data sets. The kinetic validation test cases include ignition delays, species time histories measured in shock tubes, laminar burning velocity measurements, detailed species measurements in premixed flames, and major species profiles in a plug flow reactor configuration. The ability of the present reaction mechanism in predicting different targets has been evaluated in detail.

It is worth re-emphasizing the use of several, very recent data sets for kinetic model validation in the present work. The ability of the proposed reaction scheme to adequately describe the ignition behavior for low through high temperatures is also noteworthy. Further, the pathways for the formation of aromatics from methylcyclohexane oxidation are well represented by the present model. Also, the base mechanism on which the methylcyclohexane kinetics is built, allows a detailed description of the aromatic chemistry 4. Together, this makes the present kinetic scheme well suited for assessing the formation of pollutants in engines.

One other key contribution of this work is that the proposed reaction mechanism can describe the kinetics of methylcyclohexane, as well as that of $n$-heptane, isooctane, substituted aromatics, and $n$-dodecane, considered in our previous works [1, 4, 23, which are important components of transportation fuel surrogates. In addition, the proposed reaction mechanism also retains a compact size, 369 species and 2691 reactions counting forward and reverse reactions separately, which makes kinetic analysis feasible using this model. This size of the reaction mechanism is suitable to be coupled in LES simulations employing flamelet models with tabulation [2], which expands the usability of the kinetic scheme to real-time simulations.

The model described here, as well as a derived model relevant to high temperature oxidation only, along with the corresponding thermodynamic and transport properties have been made available as Supporting Materials. The performance of this high temperature model has been verified to be similar to the complete model at $T>1100 \mathrm{~K}$. The validation cases used in this work were repeated for this high temperature model, and are made available with the Supporting materials (Figs. S34-S40) for the sake of completeness.

\section{Acknowledgements}

The first and the third author gratefully acknowledge funding by the AFOSR and NASA, in addition to support by SERDP under grant WP-2151 with Dr. Robin Nissan as the program manager. The third author also acknowledges support from the German Research Foundation (DFG) within the Collaborative Research Centre SFB 686 - Model-Based Control of Homogenized LowTemperature Combustion at RWTH Aachen University, Germany, and Bielefeld University, Germany. This material is also based upon work supported by the U.S. Department of Energy, Office of Science, Office of Basic Energy 


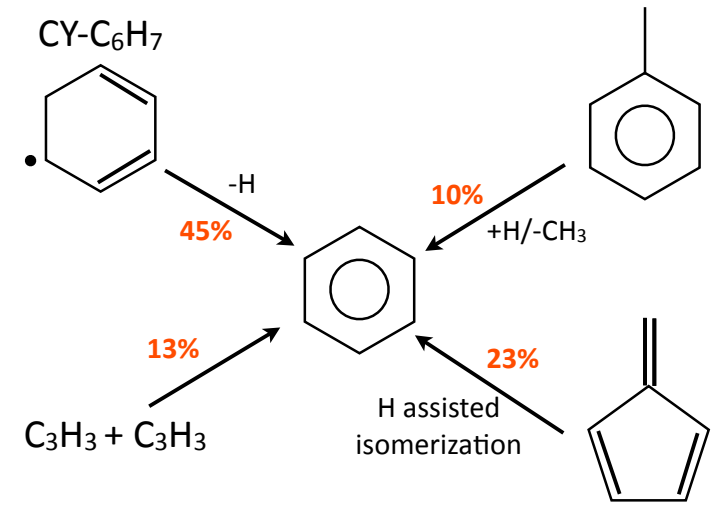

(a) Benzene formation pathways
MCHJDE

A representative species

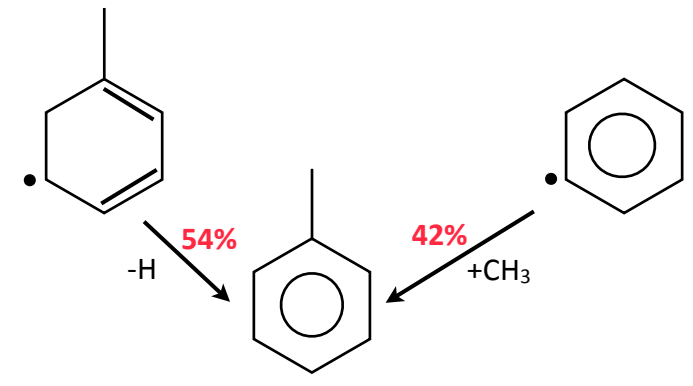

(b) Toluene formation pathways

Figure 20: Main reaction pathways forming benzene and toluene in the rich flame $(\phi=1.75$ and $P=30$ torr $)$ investigated in section 3.5 The step-wise dehydrogenation pathways (shown in Fig. 7) involving intermediates in the methylcyclohexane sub-mechanism contribute significantly to benzene and toluene at these conditions. In addition, the aromatic chemistry well described in the base mechanism 1, 4 on top of which the methylcyclohexane chemistry has been built in the present work, is also crucial to the formation of benzene and toluene.

Sciences, under Award Number DE-FG02-90ER14128. The authors would like to thank Dr. Fei Qi, Zhandong Wang, and their co-workers for sharing their raw measurements for species profiles in flames and permitting to use their experimental data. The authors are also grateful to Prof. Elizabeth Fisher for her assistance in testing the mechanism files in chemkin format. The authors would also like to acknowledge the insightful comments of the reviewers, which helped improve the quality of this article significantly.

\section{References}

[1] G. Blanquart, P. Pepiot-Desjardins, H. Pitsch, Chemical mechanism for high temperature combustion of engine relevant fuels with emphasis on soot precursors, Combust. Flame 156 (2009) 588-607.

[2] T. Edwards, Kerosene fuels for aerospace propulsioncomposition and properties, in: $38^{\text {th }}$ AIAA/ASME/SAE/ASEE Joint Propulsion Conference \& Exhibit, 2002, pp. 2002-3872.

[3] L. M. Shafer, R. C. Striebich, J. Gomach, T. Edwards, Chemical class composition of commercial jet fuels and other specialty kerosene fuels, in: $14^{\text {th }}$ AIAA/AHI Space Planes and Hypersonic Systems and Technologies Conference, 2006, pp. 20067972.

[4] K. Narayanaswamy, G. Blanquart, H. Pitsch, A consistent chemical mechanism for the oxidation of substituted aromatic species, Combust. Flame 157 (10) (2010) 1879-1898.

[5] A. Burcat, C. Snyder, T. Brabbs, Ignition delay times of benzene and toluene with oxygen in argon mixtures, Tech. rep., NASA (1986).

[6] H.-P. S. Shen, J. Vanderover, M. A. Oehlschlaeger, A shock tube study of the auto-ignition of toluene/air mixtures at high pressures, Proceedings of the Combustion Institute 32 (2009) $165-172$.

[7] H.-P. S. Shen, M. A. Oehlschlaeger, The autoignition of $\mathrm{C}_{8} \mathrm{H}_{10}$ aromatics at moderate temperatures and elevated pressures, Combust. Flame 156 (2009) 1053-1062.

[8] F. Battin-Leclerc, R. Bounaceur, N. Belmekki, P. A. Glaude, Experimental and modeling study of the oxidation of xylenes, Int. J. Chem. Kinet. 38 (2006) 284-302.

[9] S. Gail, Etude cinétique de l'oxydation de composés aromatiques en relation avec la composition du gazole et de l'essence:
Approche expérimentalé et modélisation cinétique détaillée, Ph.D. thesis, University of Orléans (2003).

[10] S. Gail, P. Dagaut, G. Black, J. M. Simmie, Kinetics of 1,2-dimethylbenzene oxidation and ignition: Experimental and detailed kinetic modeling, Comb. Sci. Tech. 180 (2008) $1748-1771$.

[11] U. Pfahl, K. Fieweger, G. Adomeit, Self-ignition of dieselrelevant hydrocarbon-air mixtures under engine conditions, Symp. (Int.) Combust. 26 (1) (1996) 781-789.

[12] V. Vasudevan, D.F.Davidson, R. Hanson, Shock tube measurements of toluene ignition times and $\mathrm{OH}$ concentration time histories, Proc. Combust. Inst. 30 (2005) 1155-1163.

[13] R. Sivaramakrishnan, R. S. Tranter, K. Brezinsky, High pressure, high temperature oxidation of toluene, Combust. Flame 139 (2004) 340-350.

[14] R. Sivaramakrishnan, R. S. Tranter, K. Brezinsky, High pressure pyrolysis of toluene. 1. experiments and modeling of toluene decomposition, J. Phys. Chem. A. 110 (2006) 9388-9399.

[15] D. Klotz, K. Brezinsky, I. Glassman, Modeling the combustion of toluene-butane blends, Proc. Combust. Inst. 27 (1998) 337344.

[16] T. A. Litzinger, K. Brezinsky, I. Glassman, The oxidation of ethylbenzene near 1060K, Combust. Flame 63 (1986) 251-267.

[17] J. Emdee, K. Brezinsky, I. Glassman, High-temperature oxidation mechanisms of $m$ - and $p$-xylene, J. Phys. Chem. 95(4) (1991) 1626-1635.

[18] C. B. Shaddix, K. Brezinsky, I. Glassman, Oxidation of 1methylnaphthalene, Proc. Combust. Inst. 24 (1992) 683-690.

[19] S. G. Davis, C. K. Law, Determination of and fuel structure effects on laminar flame speeds of $\mathrm{C}_{1}$ to $\mathrm{C}_{8}$ hydrocarbons, Comb. Sci. Tech. 140(1) (1998) 427-449.

[20] R. Johnston, J. Farrell, Laminar burning velocities and markstein lengths of aromatics at elevated temperature and pressure, Proc. Combust. Inst. 30 (2005) 217-224.

[21] T. Hirasawa, C. J. Sung, A. Joshi, Z. Yang, H. Wang, C.K.Law, Determination of laminar flame speeds using digital particle image velocimetry: Binary fuel blends of ethylene, $n$-butane and toluene, Proc. Combust. Inst. 29 (2002) 1427-1434.

[22] C. Ji, A. Moheet, Y. L. Wang, M. Colket, H. Wang, F. N. Egolfopoulos, An experimental study of premixed $m$-Xylene/Air and $n$-Dodecane $/ \mathrm{m}$-Xylene/Air flames, Proceedings of the 6 th U.S. National combustion meet, University of Michigan, 2009.

[23] K. Narayanaswamy, P. Pepiot, H. Pitsch, A chemical mechanism for low to high temperature oxidation of $n$-dodecane as a component of transportation fuel surrogates, Combust. Flame 161 (4) (2014) 866-884. 
[24] T. Edwards, L. Q. Maurice, Surrogate mixtures to represent complex aviation and rocket fuels, J. Prop. Power 17 (2000) 461-466.

[25] T. Edwards, Liquid fuels and propellants for aerospace propulsion: 1903-2003, Journal of Propulsion and Power 19 (6) (2003) 1089-1107.

[26] Y. Briker, Z. Ring, A. Iacchelli, N. McLean, P. Rahimi, C. Fairbridge, R. Malhotra, M. Coggiola, S. Young, Diesel fuel analysis by gc-fims: aromatics, n-paraffins, and isoparaffins, Energy \& Fuels 15 (1) (2001) 23-37.

[27] H. Zhang, E. Eddings, A. Sarofim, Criteria for selection of components for surrogates of natural gas and transportation fuels, Proc. Combust. Inst. 31 (2007) 401-409.

[28] S. Granata, T. Faravelli, E. Ranzi, A wide range kinetic modeling study of the pyrolysis and combustion of naphthenes, Combust. Flame. 132 (3) (2003) 533-544.

[29] S. Zeppieri, K. Brezinsky, I. Glassman, Pyrolysis studies of Methylcyclohexane and Oxidation studies of Methylcyclohexane and Methylcyclohexane/Toluene blends, Combust. Flame 108 (2009) 266-286.

[30] J. P. Orme, H. J. Curran, J. M. Simmie, Experimental and modeling study of methyl cyclohexane pyrolysis and oxidation, J. Phys. Chem. A. 110 (2006) 114-131.

[31] W. J. Pitz, C. V. Naik, T. N. Mhaolduin, C. K. Westbrook, H. J. Curran, J. P. Orme, J. M. Simmie, Modeling and experimental investigation of methylcyclohexane ignition in a rapid compression machine, Proc. Combust. Inst. 31 (1) (2007) 267 275.

[32] H. Wang, E. Dames, B. Sirjean, D. A. Sheen, R. Tangko, A. Violi, J. Y. W. Lai, F. N. Egolfopoulos, D. F. Davidson, R. K. Hanson, C. T. Bowman, C. K. Law, W. Tsang, N. P. Cernansky, D. L. Miller, R. P. Lindstedt, A hightemperature chemical kinetic model of $n$-alkane (up to $n$ dodecane), cyclohexane, and methyl-, ethyl-, $n$-propyl and $n$ butyl-cyclohexane oxidation at high temperatures, JetSurF version 2.0, http://web.stanford.edu/group/haiwanglab/JetSurF/ (September 19 2010).

[33] Z. Wang, L. Ye, W. Yuan, L. Zhang, Y. Wang, Z. Cheng, F. Zhang, F. Qi, Experimental and kinetic modeling study on methylcyclohexane pyrolysis and combustion, Combust. Flame. (in press)

[34] B. W. Weber, W. J. Pitz, M. Mehl, E. J. Silke, A. C. Davis, C.-J. Sung, Experiments and modeling of the autoignition of methylcyclohexane at high pressure, Combust. Flame (in press).

[35] Z. Hong, K. Y. Lam, D. F. Davidson, R. K. Hanson, A comparative study of the oxidation characteristics of cyclohexane, methylcyclohexane, and $n$-butylcyclohexane at high temperatures, Combust. Flame. 158 (2011) 1456-1468.

[36] K. Kumar, C. Sung, Flame propagation and extinction characteristics of neat surrogate fuel components, Energy \& Fuels 24 (7) (2010) 3840-3849.

[37] D. Singh, T. Nishiie, L. Qiao, Laminar flame speeds and markstein lengths of $n$-Decane/Air, $n$-Decane $/ \mathrm{O}_{2} / \mathrm{He}$ and $\mathrm{MCH} / \mathrm{Air}$ flames, in: Central States Meeting, 2010.

[38] C. Ji, E. Dames, B. Sirjean, H. Wang, F. N. Egolfopoulos, An experimental and modeling study of the propagation of cyclohexane and mono-alkylated cyclohexane flames, Proc. Combust. Inst. 33 (2011) 971-978.

[39] F. Wu, A. P. Kelley, C. K. Law, Laminar flame speeds of cyclohexane and mono-alkylated cyclohexanes at elevated pressures, Combust. Flame. 159 (4) (2012) 1417-1425.

[40] S. A. Skeen, B. Yang, A. W. Jasper, W. J. Pitz, N. Hansen, Chemical structures of low-pressure premixed methylcyclohexane flames as benchmarks for the development of a predictive combustion chemistry model, Energy \& Fuels 25 (12) (2011) 5611-5625.

[41] Y. Yang, A. L. Boehman, Experimental study of cyclohexane and methylcyclohexane oxidation at low to intermediate temperature in a motored engine, Proc. Combust. Inst. 32 (1) (2009) 419-426.

[42] Y. Yang, A. L. Boehman, J. M. Simmie, Effects of molecular structure on oxidation reactivity of cyclic hydrocarbons: Experimental observations and conformational analysis, Combust. Flame 157 (12) (2010) 2369-2379.

[43] P. Pepiot-Desjardins, H. Pitsch, An efficient error propagation based reduction method for large chemical kinetic mechanisms, Combust. Flame 154 (2008) 67-81.

[44] P. Pepiot-Desjardins, H. Pitsch, An automatic chemical lumping method for the reduction of large chemical kinetic mechanisms, Combust. Theory. Mod. 12 (6) (2008) 1089-1108.

[45] S. S. Ahmed, F. Mauß, G. Moréac, T. Zeuch, A comprehensive and compact $n$-heptane oxidation model derived using chemical lumping, Phys. Chem. Chem. Phys. 9 (9) (2007) 1107-1126.

[46] P. Pepiot-Desjardins, Automatic strategies to model transportation fuel surrogates, Ph.D. thesis, Stanford University, Department of Mechanical Engineering (2008).

[47] M. P. Burke, M. Chaos, Y. Ju, F. L. Dryer, S. J. Klippenstein, Comprehensive $\mathrm{H}_{2} / \mathrm{O}_{2}$ kinetic model for high-pressure combustion, Int. J. Chem. Kinet. 44 (7) (2012) 444-474.

48] S. S. Vasu, D. F. Davidson, Z. Hong, V. Vasudevan, R. K. Hanson, Shock tube study of methylcyclohexane ignition over a wide range of pressure and temperature, Energy \& Fuels 23 (2009) 175-185.

[49] S. S. Vasu, D. F. Davidson, R. K. Hanson, OH time-histories during oxidation of $n$-Heptane and Methylcyclohexane at high pressures and temperatures, Combust. Flame 156 (2009) 736749.

[50] F. Zhang, Z. Wang, Z. Wang, L. Zhang, Y. Li, F. Qi, Kinetics of decomposition and isomerization of methylcyclohexane: Starting point for studying monoalkylated cyclohexanes combustion, Energy \& Fuels 27 (3) (2013) 1679-1687.

[51] D. M. Matheu, W. H. Green, J. M. Grenda, Capturing pressuredependence in automated mechanism generation: Reactions through cycloalkyl intermediates, International journal of chemical kinetics 35 (3) (2003) 95-119.

$52]$ B. Sirjean, P. A. Glaude, M. F. Ruiz-Lopez, R. Fournet, Theoretical kinetic study of thermal unimolecular decomposition of cyclic alkyl radicals, J. Phys. Chem. A. 112 (46) (2008) 11598 11610 .

[53] S. M. Sarathy, C. K. Westbrook, M. Mehl, W. J. Pitz, C. Togbe, P. Dagaut, H. Wang, M. A. Oehlschlaeger, U. Niemann, K. Seshadri, Comprehensive chemical kinetic modeling of the oxidation of 2-methylalkanes from $\mathrm{C}_{7}$ to $\mathrm{C}_{20}$, Combust. Flame 158 (12) (2011) 2338-2357.

54] C. K. Westbrook, W. J. Pitz, O. Herbinet, H. J. Curran, E. J. Silke, A detailed chemical kinetic reaction mechanism for $n$ alkane hydrocarbons from $n$-octane to $n$-hexadecane, Combust. Flame 156 (1) (2009) 181-199.

[55] C. Y. Sheng, J. W. Bozzelli, A. M. Dean, A. Y. Chang, Detailed kinetics and thermochemistry of c2h5 $+\mathrm{o} 2$ : Reaction kinetics of the chemically-activated and stabilized $\mathrm{CH}_{3} \mathrm{CH}_{2} \mathrm{OO}$ adduct, J. Phys. Chem. A 106 (32) (2002) 7276-7293.

[56] H.-H. Carstensen, C. V. Naik, A. M. Dean, Detailed modeling of the reaction of $\mathrm{C}_{2} \mathrm{H}_{5}+\mathrm{O}_{2}$, The Journal of Physical Chemistry A 109 (10) (2005) 2264-2281.

[57] E. G. Estupiñán, S. J. Klippenstein, C. A. Taatjes, Measurements and modeling of $\mathrm{HO}_{2}$ formation in the reactions of $n$ $\mathrm{C}_{3} \mathrm{H}_{7}$ and $i-\mathrm{C}_{3} \mathrm{H}_{7}$ radicals with $\mathrm{O}_{2}$, J. Phys. Chem. B 109 (17) (2005) 8374-8387.

[58] E. J. Silke, W. J. Pitz, C. K. Westbrook, M. Ribaucour, Detailed chemical kinetic modeling of cyclohexane oxidation, J. Phys. Chem. A. 111 (19) (2007) 3761-3775.

[59] Y. Yang, A. L. Boehman, J. M. Simmie, Uniqueness in the low temperature oxidation of cycloalkanes, Combustion and Flame 157 (12) (2010) 2357-2368.

60] C. Cavallotti, R. Rota, T. Faravelli, E. Ranzi, Ab initio evaluation of primary cyclo-hexane oxidation reaction rates, Proceedings of the Combustion Institute 31 (1) (2007) 201-209.

[61] H. J. Curran, P. Gaffuri, W. J. Pitz, C. K. Westbrook, A comprehensive modeling study of iso-octane oxidation, Combust. Flame 129 (3) (2002) 253-280.

[62] M. Mehl, W. J. Pitz, C. K. Westbrook, H. J. Curran, Kinetic 
modeling of gasoline surrogate components and mixtures under engine conditions, Proc. Combust. Inst. 33 (1) (2011) 193-200.

[63] S. Peukert, C. Naumann, M. Braun-Unkhoff, U. Riedel, The reaction of cyclohexane with h-atoms: A shock tube and modeling study, International Journal of Chemical Kinetics 44 (2) (2012) 130-146.

[64] R. Sivaramakrishnan, J. Michael, Shock tube measurements of high temperature rate constants for $\mathrm{OH}$ with cycloalkanes and methylcycloalkanes, Combust. Flame. 156 (5) (2009) 1126-1134.

[65] C. Cavallotti, S. Fascella, R. Rota, S. Carra, A quantum chemistry study of the formation of pah and soot precursors through butadiene reactions, Combustion science and technology 176 (56) (2004) 705-720.

[66] H. R. Zhang, L. K. Huynh, N. Kungwan, Z. Yang, S. Zhang, Combustion modeling and kinetic rate calculations for a stoichiometric cyclohexane flame. 1. major reaction pathways, J. Phys. Chem. A. 111 (19) (2007) 4102-4115.

[67] H. Pitsch, M. Bollig, Flamemaster, a computer code for homogeneous and one-dimensional laminar flame calculations, Institut fur Technische Mechanik, RWTH Aachen.

[68] J. Vanderover, M. A. Oehlschlaeger, Ignition time measurements for methylcylcohexane-and ethylcyclohexane-air mixtures at elevated pressures, Int. J. Chem. Kinet. 41 (2) (2009) $82-91$.

[69] Z. Wang, L. Ye, L. Zhang, F. Zhang, J. Yang, H. Jin, Y. Li, K. Kohse-Höinghaus, F. Qi, An experimental and kinetic modeling study on premixed methylcyclohexane flames at low pressure, Proceedings of the European Combustion Meeting.

[70] A. M. Mebel, E. W. G. Diau, M. C. Lin, K. Morokuma, Ab initio and RRKM calculations for multichannel rate constants of the $\mathrm{C}_{2} \mathrm{H}_{3}+\mathrm{O}_{2}$ reaction, Journal of the American Chemical Society 118 (40) (1996) 9759-9771.

[71] S. Fischer, F. Dryer, H. Curran, The reaction kinetics of dimethyl ether. i: High-temperature pyrolysis and oxidation in flow reactors, International Journal of Chemical Kinetics 32 (12) (2000) 713-740.

[72] M. E. Mueller, H. Pitsch, Large eddy simulation of soot evolution in an aircraft combustor, Phys. Fluids 25 (110812) (2013) $1-21$. 